\title{
Retrieval and validation of carbon dioxide, methane and water vapor for the Canary Islands IR-laser occultation experiment
}

\author{
V. Proschek ${ }^{1}$, G. Kirchengast ${ }^{1}$, S. Schweitzer ${ }^{2,1}$, J. S. A. Brooke ${ }^{3}$, P. F. Bernath ${ }^{4,3}$, C. B. Thomas ${ }^{3}$, J.-G. Wang ${ }^{3}$, \\ K. A. Tereszchuk ${ }^{5,3}$, G. González Abad ${ }^{6,3}$, R. J. Hargreaves ${ }^{4,3}$, C. A. Beale ${ }^{4,3}$, J. J. Harrison ${ }^{3}$, P. A. Martin , $^{7}$ \\ V. L. Kasyutich ${ }^{8,7}$, C. Gerbig ${ }^{9}$, O. Kolle ${ }^{9}$, and A. Loescher ${ }^{10}$ \\ ${ }^{1}$ Wegener Center for Climate and Global Change (WEGC) and Institute for Geophysics, \\ Astrophysics and Meteorology/Institute of Physics, University of Graz, Graz, Austria \\ ${ }^{2}$ Institute for Surface Technologies and Photonics, Joanneum Research Forschungsgesellschaft mbH, Weiz, Austria \\ ${ }^{3}$ Department of Chemistry, University of York, York, UK \\ ${ }^{4}$ Department of Chemistry and Biochemistry, Old Dominion University, Norfolk, Virginia, USA \\ ${ }^{5}$ Environment Canada, Toronto, Ontario, Canada \\ ${ }^{6}$ Harvard-Smithsonian Center for Astrophysics, Cambridge, Massachusetts, USA \\ ${ }^{7}$ School of Chemical Engineering and Analytical Science, University of Manchester, Manchester, UK \\ ${ }^{8}$ Servomex, Jarvis Brook, Crowborough, UK \\ ${ }^{9}$ Biogeochemical Systems Department, Max Planck Institute for Biogeochemistry, Jena, Germany \\ ${ }^{10}$ Earth Observation Future Missions Division, ESA/ESTEC, Noordwijk, the Netherlands \\ Correspondence to: V. Proschek (veronika.proschek@uni-graz.at)
}

Received: 19 May 2014 - Published in Atmos. Meas. Tech. Discuss.: 21 November 2014

Revised: 1 July 2015 - Accepted: 24 July 2015 - Published: 14 August 2015

\begin{abstract}
The first ground-based experiment to prove the concept of a novel space-based observation technique for microwave and infrared-laser occultation between low-Earthorbit satellites was performed in the Canary Islands between La Palma and Tenerife. For two nights from 21 to 22 July 2011 the experiment delivered the infrared-laser differential transmission principle for the measurement of greenhouse gases (GHGs) in the free atmosphere. Such global and long-term stable measurements of GHGs, accompanied also by measurements of thermodynamic parameters and line-of-sight wind in a self-calibrating way, have become very important for climate change monitoring. The experiment delivered promising initial data for demonstrating the new observation concept by retrieving volume mixing ratios of GHGs along a $\sim 144 \mathrm{~km}$ signal path at altitudes of $\sim 2.4 \mathrm{~km}$. Here, we present a detailed analysis of the measurements, following a recent publication that introduced the experiment's technical setup and first results for an example retrieval of $\mathrm{CO}_{2}$. We present the observational and validation data sets, the latter simultaneously measured at the transmit-
\end{abstract}

ter and receiver sites; the measurement data handling; and the differential transmission retrieval procedure. We also determine the individual and combined uncertainties influencing the results and present the retrieval results for ${ }^{12} \mathrm{CO}_{2},{ }^{13} \mathrm{CO}_{2}$, $\mathrm{C}^{18} \mathrm{OO}, \mathrm{H}_{2} \mathrm{O}$ and $\mathrm{CH}_{4}$. The new method is found to have a reliable basis for monitoring of greenhouse gases such as $\mathrm{CO}_{2}, \mathrm{CH}_{4}$, and $\mathrm{H}_{2} \mathrm{O}$ in the free atmosphere.

\section{Introduction}

Several in situ and remote-sensing measurement principles have already been applied for long-term greenhouse gas (GHG) monitoring from ground-based stations, airplanes, and even satellites. The most widely known long-term in situ, ground-based $\mathrm{CO}_{2}$ measurements have been made at the Mauna Loa Observatory (Keeling, 1970). Measurements have been ongoing for some decades now, recording the anthropogenically induced increases in atmospheric $\mathrm{CO}_{2}$ levels (From and Keeling, 1986; Heimann, 2005). Numerous com- 


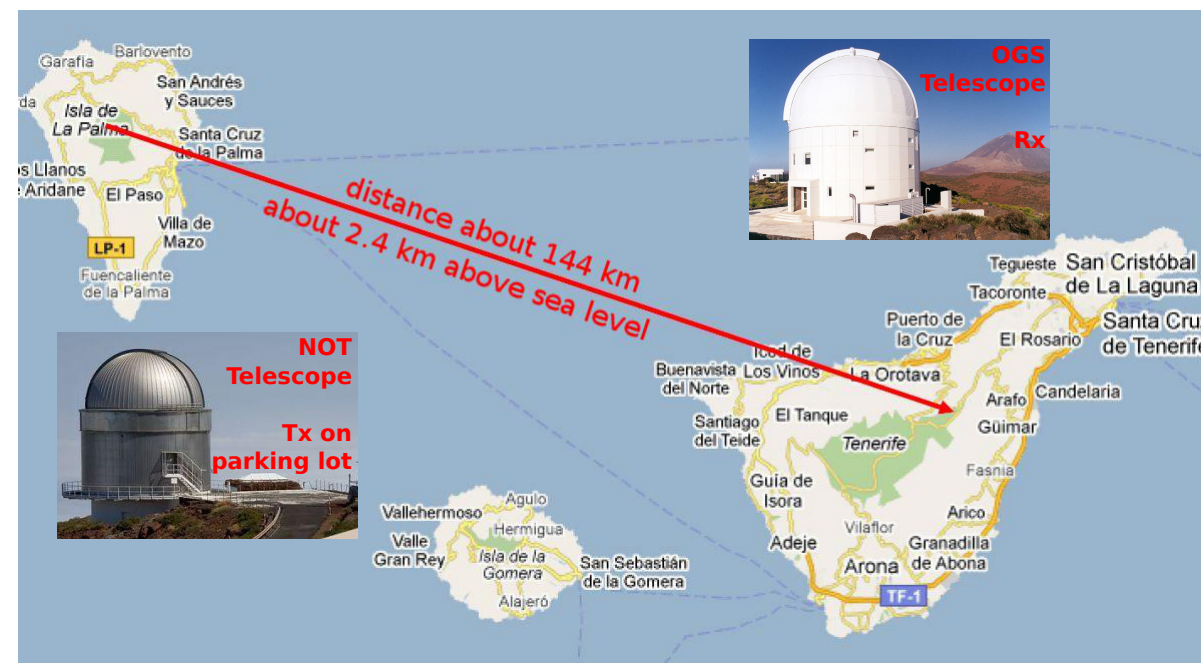

Figure 1. Schematic view of the $\sim 144 \mathrm{~km}$ long-range infrared-laser link between La Palma (Tx) and Tenerife (Rx) and illustrative pictures of the NOT parking lot location and the OGS telescope.

plementary ground-based (Yang et al., 2002; Brailsford et al., 2012; Messerschmidt et al., 2012) or airborne (Desjardins et al., 1989; Gurk et al., 2008; Vadrevu and Choi, 2011) $\mathrm{CO}_{2}$ measurement campaigns have been conducted for validation and calibration purposes, e.g., the Total Carbon Column Observing Network (TCCON; Wunch et al., 2010).

Instruments on satellites - e.g., IASI (Infrared Atmospheric Sounding Interferometer; Chalon et al., 2001) on MetOp, AIRS (Atmospheric InfraRed Sounder; Chahine et al., 2006) on Aqua or SCIAMACHY (SCanning Imaging Absorption spectroMeter for Atmospheric CHartographY; Bovensmann et al., 1999) on Envisat until 2012 - and missions like GOSAT (Greenhouse gas Observing SATellite; Hamazaki et al., 2004; Yokota et al., 2009; Yoshida et al., 2011) measure GHGs remotely from space on a long-term basis, albeit with significant limitations in altitude resolution, geographic coverage and accuracy due to the use of passive radiometry techniques that are challenging to calibrate.

Very precise and accurate measurements of GHG concentrations and atmospheric parameters, including line-of-sight wind in the free atmosphere, self-calibrating and independent from external parameters, are needed for climate change observations. In order to serve as climate benchmark measurements, these observations need to be made over long time periods in very stable and concise ways meeting high quality standards. The new low-Earth-orbit (LEO) satellite observation concept LEO-LEO Microwave and Infrared-laser Occultation (LMIO), introduced by Kirchengast and Schweitzer (2011), provides such a measurement technique.

This active remote-sensing method uses the differential transmission principle (Kursinski et al., 2002; Gorbunov and Kirchengast, 2007; Kirchengast et al., 2010; Kirchengast and Schweitzer, 2011; Schweitzer et al., 2011a) for accurately measuring GHG concentrations. In particular, each GHG is retrieved by the use of two closely spaced frequencies within the 2.0-2.5 $\mu \mathrm{m}$ spectral range "between" the solar and terrestrial emission spectra. The broadband effects of the atmosphere - such as Rayleigh and aerosol scattering, scintillation, and even subvisible cirrus cloud absorption - are removed by subtracting a nearby reference infrared-laser signal outside the GHG absorption lines ("off signal") from an absorption signal located on a targeted GHG absorption line ("on signal"). In several studies - including Kirchengast et al. (2010), Schweitzer (2010), Schweitzer et al. (2011a, b), Proschek et al. (2011, 2014), Plach et al. (2015) and Syndergaard and Kirchengast (2015) - detailed insight is given into the mission concept, the scientific objectives, the retrieval process, and examples of retrievals that were performed.

The first proof-of-concept experiment, which is described by Brooke et al. (2012) (referred to as Betal2012 hereafter) and gives a technical overview of the ground-based experiment with preliminary results on $\mathrm{CO}_{2}$, was performed between La Palma and Tenerife in the Canary Islands in July 2011 (see Fig. 1). These sites enabled the realization of a long-path ground link $(\sim 144 \mathrm{~km})$, with both transmitter (Tx) and receiver $(\mathrm{Rx})$ locations at an altitude of $\sim 2.4 \mathrm{~km}$. The Tx platform at La Palma was mounted in the parking lot next to the Nordic Optical Telescope (NOT) and pointed towards the Rx telescope located at the Optical Ground Station (OGS) from ESA in Tenerife. At the OGS, a telescope with an aperture of $1 \mathrm{~m}$ in diameter was used to capture the infrared-laser signals, which were afterwards guided to a Rx breadboard.

The main part of the transmitter breadboard consisted of four tunable single-mode distributed feedback (DFB) lasers emitting in the shortwave infrared (SWIR) spectral range. Absorption lines of the main $\mathrm{CO}_{2}$ isotopes $\left({ }^{12} \mathrm{CO}_{2},{ }^{13} \mathrm{CO}_{2}\right.$, $\left.\mathrm{C}^{18} \mathrm{OO}\right)$ and $\mathrm{H}_{2} \mathrm{O}$ were covered by two lasers near $2.1 \mu \mathrm{m}$, 
and the other two lasers covered $\mathrm{CH}_{4}$ absorption in the spectral range near $2.3 \mu \mathrm{m}$. For the latter case, only one laser was used for the retrieval calculations in this study, since the other one was measuring at a reference-signal location somewhat away from suitable absorption lines. Both spectral windows used within $2.0-2.4 \mu \mathrm{m}$ are generally insensitive to $\mathrm{H}_{2} \mathrm{O}$ saturation, and the signals were sufficiently strong for long-path absorption by the targeted GHGs, even with relatively lowpower lasers (between 4 and $10 \mathrm{~mW}$ ).

From the Tx side, infrared spectral scans over periods of up to about $20 \mathrm{~min}$, with $4 \mathrm{~s}$ subperiods and spectral ranges of up to $2 \mathrm{~nm}$ from each of the IR lasers, were transmitted into the atmosphere. The infrared signals experienced molecular absorption and further broadband atmospheric effects, such as scintillation, aerosol and Rayleigh scattering. We could visually confirm during the experiment that these free-atmosphere and cloud-free conditions prevailed along the laser link; nevertheless we experienced variable meteorological conditions both near the Tx and Rx sites (e.g., changing wind conditions) and along the link (e.g., significant moisture changes), which we needed to take into account in the analysis and interpretation of results. The propagation beam path, for brevity termed ray path hereafter in this paper, was at all times running in the free atmosphere above the marine boundary layer, such that no low liquid clouds obscured the signals.

On the Rx side, the infrared-laser signals were captured by the OGS telescope. The signals were directed along the optical path of $39 \mathrm{~m}$ focal length into the Coudé room of the OGS, where they were focused onto the InGaAs photodiode detectors of the Rx breadboard assembly. A more detailed description of the setup and recording process is given by Betal2012.

In addition to the infrared spectra measured at the $\mathrm{Rx}$, data sets for validation were recorded. The validation measurement instruments were located close to the Tx and Rx sites as listed in Table 1, where the (GPS-derived) positions of all measurement instruments used during the campaign are listed in terms of their latitude, longitude and altitude. Together, the IR-laser spectra and the validation data from these locations provided the basis for the detailed GHG retrieval analysis and measurement performance assessment for $\mathrm{CO}_{2}$, $\mathrm{CH}_{4}$, and $\mathrm{H}_{2} \mathrm{O}$ in this study.

The study is organized as follows. Based on the observed data sets summarized in Sect. 2 and on the related data processing and GHG retrieval described in Sect. 3, a detailed uncertainty analysis is conducted (Sect. 4) and finally the GHG retrieval results are discussed (Sect. 5). Summary and conclusions are given in Sect. 6.
Table 1. GPS-derived positions of the telescopes/parking lot and the validation stations at the transmitter $(\mathrm{Tx})$ and receiver $(\mathrm{Rx})$ sites. The meteorological station near the OGS is named GONG (its customary local name) and the cavity ring-down spectrometer for in situ GHG measurements of the company Picarro is named CRDS. Table 3 provides more details on the data sets themselves.

\begin{tabular}{llccc}
\hline Site & Name & $\begin{array}{c}\text { Latitude } \\
{[\mathrm{deg}]}\end{array}$ & $\begin{array}{c}\text { Longitude } \\
{[\mathrm{deg}]}\end{array}$ & $\begin{array}{c}\text { Altitude } \\
{[\mathrm{m}]}\end{array}$ \\
\hline Tx & NOT parking lot & 28.75720 & -17.88502 & 2390 \\
& NOT meteo station & 28.75690 & -17.88498 & 2398 \\
& CRDS Picarro & 28.75660 & -17.88505 & 2390 \\
\hline Rx & OGS telescope & 28.30097 & -16.51183 & 2393 \\
& GONG meteo & 28.30058 & -16.51218 & 2393 \\
& station & & & \\
& CRDS Picarro & 28.30103 & -16.51192 & 2393 \\
& Sampling flasks & 28.30103 & -16.51192 & 2393 \\
\hline
\end{tabular}

\section{Observational and validation data sets}

\subsection{Observational data set}

In the course of the field campaign, we effectively recorded useful data sets of infrared-laser transmission spectra during two nights, 21 and 22 July 2011. We applied a "fast scan" mode $\left(400 \mathrm{~Hz}\right.$ native scan rate) for narrow $\left(\sim 1 \mathrm{~cm}^{-1}\right)$ or broadband $\left(\sim 3-4 \mathrm{~cm}^{-1}\right)$ spectral ranges. The raw data consist of alternative records of the two active lasers $(\mathrm{L} 1+\mathrm{L} 2$ or L3 + L4), which were alternatively activated for $4 \mathrm{~s}$ at any one time within the whole measurement period (of up to $\sim 20 \mathrm{~min}$ ). The spectral ranges covered by the two active lasers typically were different, but they also overlapped in some cases as some lasers were able to scan the same spectral regions. In a preprocessing, these raw data were averaged over $4 \mathrm{~s}$. A detailed description of the scanningrecording process is given by Betal2012, Sect. 2 and Appendix A therein.

The recorded set of measurements, summarized in $\mathrm{Ta}-$ ble 2, was deemed suitable for data retrieval as the measurements contained adequate absorption lines, a sufficient spectral range, and an acceptable signal-to-noise ratio (SNR). This set contains 19 data files, measured in the two nights of 21 and 22 July. At the bottom of the table, the two $\mathrm{CH}_{4}$ spectral range measurements are listed which were recorded at the end of the campaign during the night of 22 July. As can be seen from the third column of Table 2, three lasers (L1, L2, L3) effectively yielded useful absorption spectra; laser L4 covered no adequate $\mathrm{CH}_{4}$ absorption lines (see also the discussion below in Sect. 3).

The number of spectra quoted in the fourth column of Table 2 denotes the number of $4 \mathrm{~s}$ averaged spectra in a file and thus gives the number of possible single retrieval results within the respective time period. Since different data files contain different wave number ranges, narrow or broadband, 
Table 2. Preprocessed infrared-laser link data sets available for the GHG retrieval. For description see Sect. 2.1.

\begin{tabular}{|c|c|c|c|c|c|c|c|c|c|}
\hline \multirow[t]{2}{*}{ File no. } & \multirow[t]{2}{*}{ Date } & \multirow[t]{2}{*}{ Laser ID } & \multirow[t]{2}{*}{ No. of spectra } & \multicolumn{3}{|c|}{ Wave number range } & \multicolumn{3}{|c|}{ Time range } \\
\hline & & & & $v_{\text {start }}$ & $\begin{array}{l}v_{\mathrm{end}} \\
{\left[\mathrm{cm}^{-1}\right]}\end{array}$ & $\Delta v$ & $\begin{array}{l}t_{\text {start }} \\
{[\mathrm{hh}: \mathrm{n}}\end{array}$ & $\mathrm{m:ss]}$ & $\begin{array}{r}\Delta t \\
{[\mathrm{~mm}: \mathrm{ss}]}\end{array}$ \\
\hline $\mathrm{F} 1$ & $21 \mathrm{Jul}$ & $\mathrm{L} 2$ & 14 & 4768.03 & 4768.92 & 0.89 & 01:50:07 & 01:55:06 & $04: 59$ \\
\hline \multirow[t]{2}{*}{$\mathrm{F} 2$} & $21 \mathrm{Jul}$ & L1 & 22 & 4770.99 & 4774.49 & 3.50 & $02: 22: 51$ & $02: 29: 58$ & 07:07 \\
\hline & & $\mathrm{L} 2$ & 25 & 4766.37 & 4768.16 & 1.79 & $02: 22: 42$ & 02:30:07 & $07: 25$ \\
\hline \multirow[t]{2}{*}{ F3 } & $21 \mathrm{Jul}$ & L1 & 23 & 4770.98 & 4774.52 & 3.54 & $02: 31: 18$ & $02: 38: 46$ & $07: 28$ \\
\hline & & $\mathrm{L} 2$ & 24 & 4766.37 & 4768.17 & 1.80 & 02:31:09 & $02: 38: 37$ & $07: 28$ \\
\hline \multirow[t]{2}{*}{$\mathrm{F} 4$} & $21 \mathrm{Jul}$ & L1 & 7 & 4770.99 & 4774.54 & 3.55 & $02: 40: 52$ & $02: 43: 04$ & $02: 12$ \\
\hline & & $\mathrm{L} 2$ & 8 & 4766.36 & 4768.19 & 1.83 & $02: 40: 43$ & $02: 43: 12$ & $02: 29$ \\
\hline F5 & $21 \mathrm{Jul}$ & $\mathrm{L} 1$ & 48 & 4768.45 & 4769.34 & 0.89 & 03:27:09 & $03: 41: 49$ & $14: 40$ \\
\hline \multirow{2}{*}{ F6 } & $21 \mathrm{Jul}$ & L1 & 92 & 4768.24 & 4771.86 & 3.62 & $04: 32: 03$ & 05:04:08 & $32: 05$ \\
\hline & & $\mathrm{L} 2$ & 73 & 4763.95 & 4768.21 & 4.26 & $04: 32: 14$ & 05:03:59 & $31: 45$ \\
\hline F7 & $21 \mathrm{Jul}$ & L2 & 32 & 4768.56 & 4769.49 & 0.93 & $22: 15: 04$ & $22: 29: 15$ & $14: 11$ \\
\hline F8 & $21 \mathrm{Jul}$ & $\mathrm{L} 2$ & 19 & 4768.57 & 4769.50 & 0.93 & $22: 36: 54$ & $22: 43: 34$ & $06: 40$ \\
\hline \multirow[t]{2}{*}{ F9 } & $21 \mathrm{Jul}$ & L1 & 5 & 4770.34 & 4771.20 & 0.86 & $22: 59: 03$ & 23:00:10 & 01:07 \\
\hline & & $\mathrm{L} 2$ & 3 & 4768.48 & 4769.42 & 0.94 & $22: 59: 28$ & 23:00:02 & $00: 36$ \\
\hline \multirow[t]{2}{*}{ F10 } & $21 \mathrm{Jul}$ & L1 & 49 & 4770.36 & 4771.20 & 0.84 & $23: 19: 57$ & $23: 34: 52$ & $14: 55$ \\
\hline & & $\mathrm{L} 2$ & 38 & 4768.48 & 4769.44 & 0.96 & $23: 20: 06$ & $23: 34: 42$ & $14: 36$ \\
\hline \multirow[t]{2}{*}{ F11 } & $22 \mathrm{Jul}$ & $\mathrm{L} 1$ & 38 & 4768.27 & 4771.75 & 3.48 & $00: 14: 34$ & $00: 33: 05$ & $18: 31$ \\
\hline & & $\mathrm{L} 2$ & 36 & 4763.99 & 4767.97 & 3.98 & $00: 14: 19$ & $00: 32: 54$ & $18: 35$ \\
\hline \multirow[t]{2}{*}{ F12 } & $22 \mathrm{Jul}$ & L1 & 17 & 4768.19 & 4771.79 & 3.60 & $00: 33: 53$ & $00: 42: 53$ & 09:00 \\
\hline & & $\mathrm{L} 2$ & 19 & 4764.11 & 4768.15 & 4.04 & 00:34:04 & $00: 43: 04$ & 09:00 \\
\hline \multirow[t]{2}{*}{ F13 } & $22 \mathrm{Jul}$ & L1 & 48 & 4770.92 & 4774.52 & 3.60 & $00: 54: 17$ & $01: 12: 47$ & $18: 30$ \\
\hline & & $\mathrm{L} 2$ & 37 & 4766.36 & 4768.19 & 1.83 & $00: 54: 28$ & $01: 12: 36$ & 18:08 \\
\hline \multirow[t]{2}{*}{ F14 } & $22 \mathrm{Jul}$ & L1 & 10 & 4770.92 & 4774.54 & 3.62 & $01: 14: 28$ & 01:17:59 & $03: 31$ \\
\hline & & $\mathrm{L} 2$ & 8 & 4766.37 & 4768.19 & 1.82 & $01: 14: 42$ & $01: 17: 45$ & 03:03 \\
\hline \multirow[t]{2}{*}{ F15 } & $22 \mathrm{Jul}$ & L1 & 18 & 4773.81 & 4777.55 & 3.74 & $01: 31: 29$ & $01: 37: 50$ & $06: 21$ \\
\hline & & $\mathrm{L} 2$ & 14 & 4766.36 & 4768.19 & 1.83 & $01: 31: 40$ & 01:38:01 & $06: 21$ \\
\hline \multirow[t]{2}{*}{ F16 } & $22 \mathrm{Jul}$ & $\mathrm{L} 1$ & 34 & 4773.83 & 4777.59 & 3.76 & 01:56:06 & 02:08:53 & $12: 47$ \\
\hline & & $\mathrm{L} 2$ & 25 & 4766.37 & 4768.20 & 1.83 & $01: 56: 17$ & 02:08:42 & $12: 25$ \\
\hline F17 & $22 \mathrm{Jul}$ & $\mathrm{L} 2$ & 34 & 4768.68 & 4769.60 & 0.92 & $02: 55: 54$ & 03:09:07 & $13: 13$ \\
\hline F18 & $22 \mathrm{Jul}$ & L3 & 28 & 4346.50 & 4347.45 & 1.95 & $05: 44: 42$ & $05: 51: 25$ & $06: 43$ \\
\hline F19 & $22 \mathrm{Jul}$ & L3 & 47 & 4345.94 & 4348.83 & 2.89 & $06: 21: 09$ & $06: 37: 49$ & $16: 40$ \\
\hline
\end{tabular}

the starting $\left(v_{\text {start }}\right)$ and ending $\left(v_{\text {end }}\right)$ wave numbers and associated range widths $(\Delta v)$ are given as well. Furthermore, the duration of each of the recorded measurements is shown in the last three columns of Table 2 . These columns represent the start time of the first $4 \mathrm{~s}$ scan $\left(t_{\text {start }}\right)$, the end $4 \mathrm{~s}$ scan $\left(t_{\text {end }}\right)$ and the total time $(\Delta t)$ for each laser in the associated file.

Since the spectra were preprocessed and underwent basic quality control (Betal2012, Appendix A therein), the recording time per data file varied from approximately $\sim 1 \mathrm{~min}$ up to nearly $30 \mathrm{~min}$, depending on the stability of the conditions during the measurements. Hence, the files contain from just 3 up to more than 90 successfully processed 4 s spectra. Putting the SNR achieved for this basic $4 \mathrm{~s}$ averaging period of the experiment into context with the actual spaceborne LMIO method, the latter still achieves higher SNR with its $2 \mathrm{~ms}$ averaging period during the fast vertical scan through the atmo- sphere, since its Tx-to-Rx link power budget is more favorable (Schweitzer et al., 2011a, Sect. 3.7 therein).

\subsection{Validation data set}

A crucial complementary part of the measurement campaign was the recording of validation data to support the proof of concept of the GHG retrieval results from the long-range infrared-laser link. Two different measurement instrument sources on the Tx site and three on the Rx site enabled a validation of the GHG concentrations retrieved from the measured IR-laser data. Therefore it is important to take into account also limitations of the representativeness of these local measurements for the concentrations averaged over the IRlaser link. The data sources are listed in Table 3.

At the Tx site, we obtained meteorological data as a continuous 1 min sampled data set from the NOT weather sta- 
Table 3. Validation data set taken, or used from available sources, during the measurement campaign. For description see Sect. 2.2 .

\begin{tabular}{|c|c|c|c|}
\hline & Tx (NOT) & $\mathrm{Rx}(\mathrm{OGS})$ & Notes \\
\hline $\begin{array}{l}\text { Meteo } \\
\text { data }\end{array}$ & $\begin{array}{l}\text { NOT station } \\
p, T, \mathrm{RH}, V\end{array}$ & $\begin{array}{l}\text { GONG station } \\
p, T, \mathrm{RH}, V\end{array}$ & Continuous measurements \\
\hline $\begin{array}{l}\text { CRDS } \\
\text { Picarro }\end{array}$ & $\mathrm{CO}_{2}, \mathrm{H}_{2} \mathrm{O}, \mathrm{CH}_{4}$, & $\mathrm{CO}_{2}, \mathrm{H}_{2} \mathrm{O}, \mathrm{CH}_{4}$ & $\begin{array}{l}\text { Continuous measurements by MPI-BGC; } \\
\text { time resolution } 2.5 \mathrm{~s} \text {; precision better than } 0.1 \mathrm{ppm} \text {, } \\
1 \mathrm{ppb} \text {, and } 5 \% \text { for } \mathrm{CO}_{2}, \mathrm{CH}_{4} \text { and } \mathrm{H}_{2} \mathrm{O} \text {, respectively }\end{array}$ \\
\hline $\begin{array}{l}\text { Sampling } \\
\text { flasks }\end{array}$ & - & ${ }^{12} \mathrm{CO}_{2},{ }^{13} \mathrm{CO}_{2}, \mathrm{C}^{18} \mathrm{OO}, \mathrm{CH}_{4}$ & $\begin{array}{l}\text { Analysis performed at MPI-BGC, } \\
\text { measurement during IR signal receiving phase }\end{array}$ \\
\hline $\begin{array}{l}\text { ECMWF } \\
\text { data }\end{array}$ & interpolated va & $\begin{array}{l}\text { les at } \mathrm{Tx}, \mathrm{Rx} \text {, along ray path } \\
p, T, \mathrm{H}_{2} \mathrm{O}\end{array}$ & $\begin{array}{l}\text { Six-hourly analysis, grid resolution of } \sim 14 \mathrm{~km}(\mathrm{~T} 1279) \text {, } \\
91 \text { height levels, four UTC layers per day }\end{array}$ \\
\hline
\end{tabular}

tion, containing the pressure $(p)$ in Pa, temperature $(T)$ in $\mathrm{K}$, relative humidity $(\mathrm{RH})$ in percent, and the wind speed $(V)$ in $\mathrm{m} \mathrm{s}^{-1}$. Additionally, a CRDS (cavity ring-down spectrometer, model G1301-m, Picarro Inc., CA, USA) continuously recorded the $\mathrm{CO}_{2}, \mathrm{H}_{2} \mathrm{O}$, and $\mathrm{CH}_{4}$ dry-air mole fraction in parts per million (ppm), at a time resolution of $2.5 \mathrm{~s}$. CRDS measurement accuracy was within the compatibility targets of $0.1 \mathrm{ppm}\left(\mathrm{CO}_{2}\right), 2 \mathrm{ppb}\left(\mathrm{CH}_{4}\right)$, and $5 \%\left(\mathrm{H}_{2} \mathrm{O}\right)$ (WMO, 2012). The CRDS was calibrated before and after the campaign against ambient air standards traceable to the respective WMO scales for $\mathrm{CH}_{4}$ and $\mathrm{CO}_{2}$, and against a NIST traceable dewpoint mirror for $\mathrm{H}_{2} \mathrm{O}$; no significant drift was observed. In this paper we refer to volume mixing ratio $(\mathcal{V})$ in parts per million by volume (ppmv), since this is the unit given for our retrieval results, rather than to mole fraction (the differences being not relevant for the limited accuracy needed here). The inlet of the CRDS was installed about $2 \mathrm{~m}$ above the roof of the NOT service building, aiming at locally undisturbed and clean air conditions.

At the Rx site, the same set of meteorological observables as at the Tx site was available from the weather station of the Global Oscillation Network Group (GONG), comprising $p$, $T, \mathrm{RH}$ and $V$ again as 1 min sampled data. A second CRDS instrument installed at the Rx site recorded the same set of GHGs as at the Tx site, and with the same time resolution and accuracy. In this case, the inlet was mounted $2 \mathrm{~m}$ over the ground and about $4 \mathrm{~m}$ from the dome of the OGS, again aiming to ensure undisturbed and clean air conditions. In addition, we collected air sample flasks at the Rx site. The inlet for these flasks was placed next to the CRDS inlet. The sample flasks were filled roughly every $3 \mathrm{~h}$ during the measurement times and were analyzed 4 months after the campaign at the gas analytics and isotope laboratories of the Max Planck Institute for Biogeochemistry (MPI-BGC) in Jena, Germany, determining the isotope ratios $\delta^{13} \mathrm{CO}_{2}$ and $\delta \mathrm{C}^{18} \mathrm{OO}$ as well as the dry-air mole fractions of $\mathrm{CH}_{4}$ with an accuracy that lies well within the compatibility goals recommended by WMO (2012) of 0.01 and $0.05 \%$, and $2 \mathrm{ppb}$, respectively.
Additionally, auxiliary three-dimensional meteorological analysis field data from the European Centre for MediumRange Weather Forecasts (ECMWF) were acquired over a $330 \mathrm{~km} \times 330 \mathrm{~km}$ area comprising the Canary Islands, providing high-resolution six-hourly analyses of the local pressure, temperature, and humidity conditions during the campaign period. These ECMWF analysis fields were used for (colocated) cross-check of the local meteorological data from the weather stations at the Tx and Rx sites, for providing the meteorological information for realistic ray tracing along the Tx-to-Rx signal propagation path, and for providing the needed ray-path-averaged meteorological parameters to determine the GHG volume mixing ratios from differential transmissions during the iteration calculations of the retrieval process (see Sect. 3.2 for details).

In Fig. 2, the validation data sets are illustrated, spanning the time of the measurement campaign during which useful transmission data were acquired. In particular, the data over the $48 \mathrm{~h}$ from 12:00 UTC on 20 July to 12:00 UTC on 22 July are shown. The vertical dotted lines indicate the three infrared-laser measurement time windows within which all measurement files summarized in Table 2 were acquired.

In the top panel of Fig. 2, where temperature and pressure are illustrated, the gray shadings indicate $\mathrm{a}+1 \%$ temperature deviation and $\mathrm{a}-1 \%$ pressure deviation, respectively. These percentage deviations correspond to the deviations of the weather station values from the co-located ECMWF values, which were found to occur in a rather stable manner from cross-checking the data during the times of infrared-laser link measurements at both the Tx and Rx locations. During the measurement times, both temperature and pressure evidently undergo rather weak fluctuations of up to about $2 \mathrm{~K}$ and $2 \mathrm{hPa}$ only; i.e., the thermodynamic conditions were fairly stable during these nights.

In the upper-middle panel, where the $\mathrm{H}_{2} \mathrm{O}$ volume mixing ratio $\left(\mathcal{V}_{\mathrm{H}_{2} \mathrm{O}}\right)$ is illustrated, the CRDS data are shown as measured (just $10 \mathrm{~min}$ averaged), while the $\mathcal{V}_{\mathrm{H}_{2} \mathrm{O}}$ from the weather stations was derived from the relative humidity, temperature, and pressure measurements by standard meteoro- 

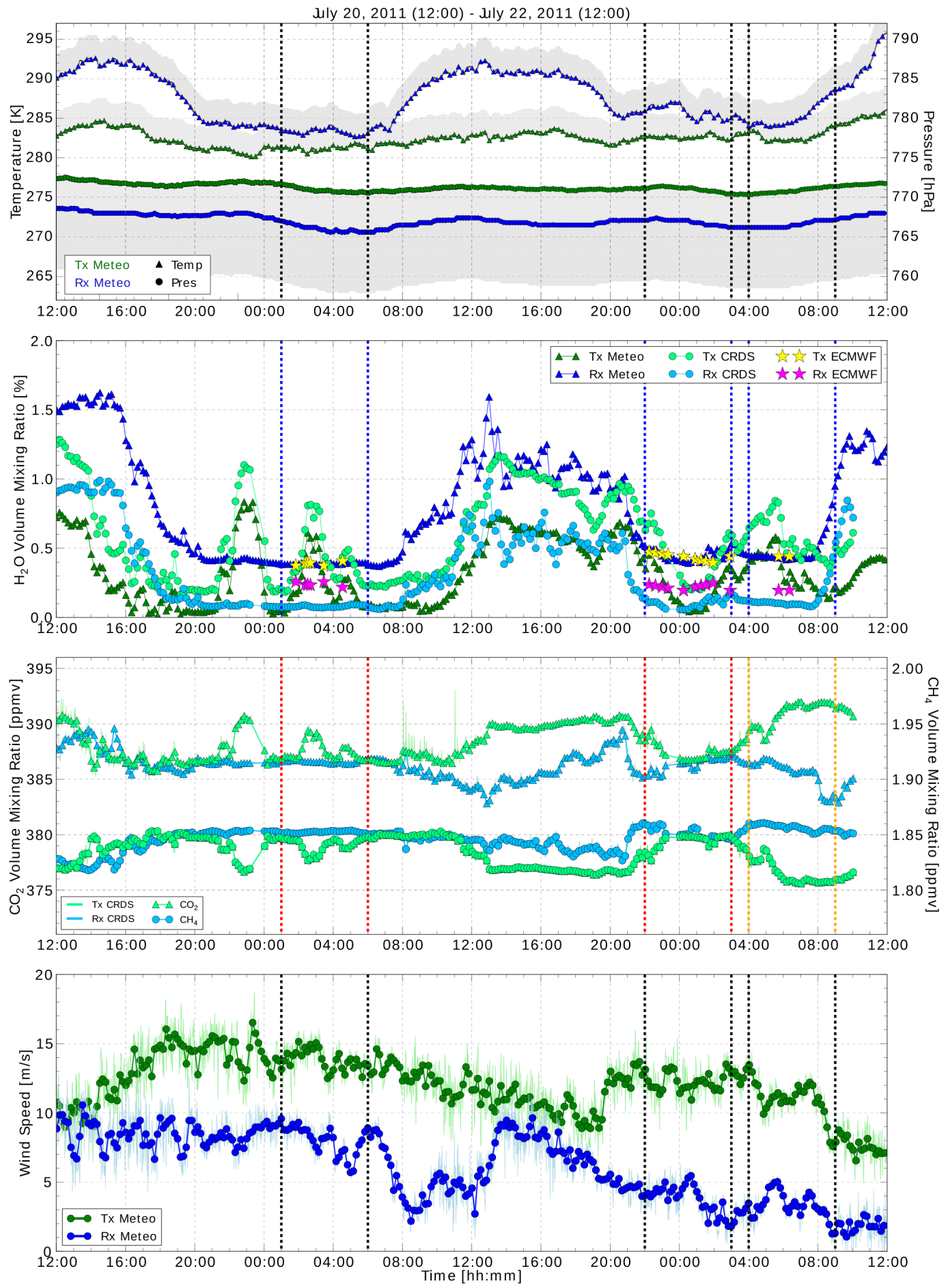

Figure 2. Time series of meteorological weather data and GHG validation data spanning the infrared-laser link measurements periods, which are delimited by dotted vertical lines (cf. times in Table 2). Top panel: $10 \mathrm{~min}$ averaged temperature (triangles) and pressure (circles) data from the weather stations at the Tx (green) and Rx (blue) sites; the gray-shaded areas indicate the respective deviations of the co-located ECMWF data at the Tx and Rx sites. Upper-middle panel: 10 min averaged $\mathrm{H}_{2} \mathrm{O}$ volume mixing ratio $(\mathcal{V})$ from the meteorological weather stations (triangles), the CRDS instruments (circles), and co-located ECMWF data (stars; those interpolated to infrared-laser link measurement times) at the Tx and Rx sites. Lower-middle panel: 10 min averaged CRDS $\mathcal{V}$ data for $\mathrm{CO}_{2}$ (triangles) and $\mathrm{CH}_{4}$ (circles) at the Tx and $\mathrm{Rx}$ sites. Bottom panel: $10 \mathrm{~min}$ averaged wind speed (circles) and underlying $1 \mathrm{~min}$ values (light-colored fluctuating time series), from the weather stations at the Tx (green) and Rx (blue) sites. 
logical equations applicable in moist air. It is evident that a significant negative deviation of the meteorological station data to the CRDS data exists at the Tx site, while a significant positive deviation occurs at the Rx site. These longer-timescale deviations seem to be systematic, while the smaller-timescale fluctuation patterns of the CRDS and the weather station data resemble each other fairly well.

Therefore, we interpret the deviations as primarily being a bias of the weather station data since the CRDS measurements underwent calibrations before and after the campaign, confirming their high accuracy as stated above. Possibly the humidity sensor of the weather station provides low accuracy, though no clarification could be found from local weather station operators. Thus, the CRDS data are considered more trustworthy. They are also in better overall agreement with the comparatively smooth ECMWF data, which show weak sensitivity regarding the local moisture variations. The reason is that the ECMWF grid resolution (about $14 \mathrm{~km})$ and time resolution $(6 \mathrm{~h})$ are much coarser than the local variability, so local variations are strongly smoothed.

In inspection of the moisture conditions during the IRlaser link measurement times, the $\mathcal{V}_{\mathrm{H}_{2} \mathrm{O}}$ data indicate a strong difference of up to about $0.8 \%$ between the Tx and Rx site. This significant horizontal variation from La Palma to Tenerife suggests assuming conservative bounds of representativity of the in situ values for the along-ray conditions. We will therefore assume a rather high relative uncertainty (of $\sim 50 \%$ ) for the knowledge of $\mathrm{H}_{2} \mathrm{O}$ concentration from the validation data, as seen below in Sect. 4 .

The lower-middle panel of Fig. 2 shows the CRDS data for $\mathrm{CO}_{2}$ and $\mathrm{CH}_{4}$, which generally exhibit somewhat stronger variability at the Tx site, indicating more capacity for localscale meteorological and composition fluctuations at this site. Furthermore, an anti-correlated link between the $\mathrm{CO}_{2}$ and $\mathrm{CH}_{4}$ variations, and also a link to the $\mathrm{H}_{2} \mathrm{O}$ variations (upper-middle panel), is clearly visible; i.e., $\mathrm{CO}_{2}$ increases are associated with $\mathrm{CH}_{4}$ decreases and $\mathrm{H}_{2} \mathrm{O}$ increases. The magnitude of the variations is small, however, both over time and regarding the differences between the Tx and Rx sites, amounting to relative changes of only about $1-2 \%$ in these well-mixed GHG volume mixing ratios.

For completeness, the bottom panel shows the wind speeds at both the Tx and Rx sites. The wind speeds at the Tx site are systematically stronger by a factor of 2 to 3 . This is primarily due to the specific topographical conditions at the $\mathrm{Tx}$ site at La Palma around the NOT parking lot, where a rather steep outer hillslope on the one side meets with a steep wall down into the volcanic crater not far away on the other side. The surroundings of the OGS telescope at Tenerife at the Rx site are much smoother; this location is characterized by an extended gentle hillslope in the surroundings. The stronger dynamics at the Tx site is also reflected in the stronger GHG dynamics noticed in the panels above, in particular during the night. The Tx wind speeds were persistently above $10 \mathrm{~m} \mathrm{~s}^{-1}$, and frequently up to about $15 \mathrm{~m} \mathrm{~s}^{-1}$, which posed challenges

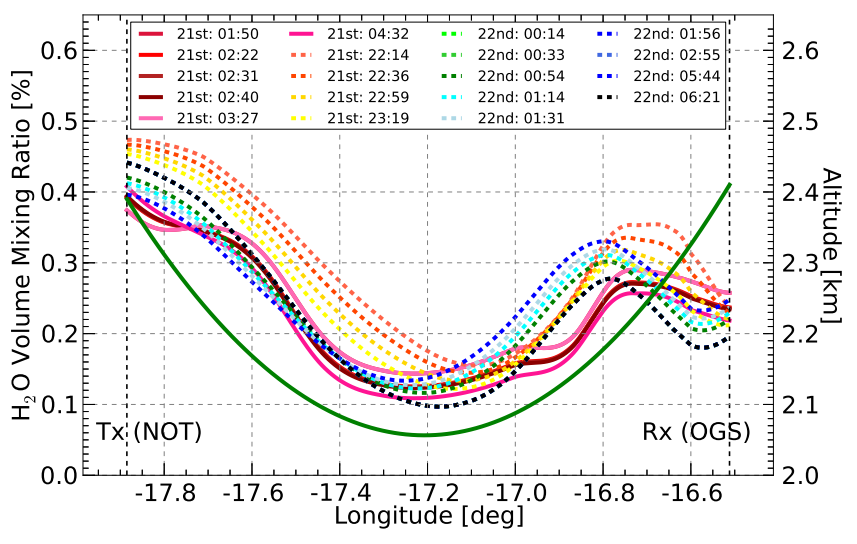

Figure 3. $\mathrm{H}_{2} \mathrm{O}$ volume mixing ratio along the Tx-to- $\mathrm{Rx}$ ray path (longitude coordinate shown) based on interpolated ECMWF analysis fields, for ray-tracing performed at the starting time of each IR-laser link data file (Table 2). In addition, the altitude of the ray path above mean sea level is indicated (thick green line; right-handside axis), which, due to Earth's curvature over the $144 \mathrm{~km}$ distance, is more than $300 \mathrm{~m}$ lower at mid-distance than the altitudes of the $\mathrm{Tx}$ and $\mathrm{Rx}$ sites.

to the stability of the Tx telescope pointing towards the OGS during the IR-laser link measurement sometimes, such that occasional re-adjustments were necessary (Betal2012).

In order to provide context information for water vapor, the most variable species along the Tx-to-Rx ray path, Fig. 3 visualizes the $\mathrm{H}_{2} \mathrm{O}$ volume mixing ratio $\left(\mathcal{V}_{\mathrm{H}_{2} \mathrm{O}}\right)$ variation along the ray path based on ECMWF analysis data. The $\mathcal{V}_{\mathrm{H}_{2} \mathrm{O}}$ values vary considerably between about 0.1 and $0.5 \%$, whereby the spread is smaller during the first measurement night than during the second night. The high horizontal variability indicated here further underscores the necessity to assign a conservative uncertainty range to the water vapor knowledge available from the validation data.

\section{Data processing setup and retrieval algorithm}

\subsection{Data processing setup}

In this section, we will explain the pre-investigations and preparation steps for the retrieval procedure. The key tool for our retrieval and for the preparatory work is the Reference Forward Model (RFM) from Dudhia (2008). This tool enables the calculation of line-by-line absorption spectra as well as forward simulations of single-line and individualfrequency transmissions and absorption coefficients for targeted GHGs. The RFM uses as a basis the HIgh-resolution TRANsmission molecular absorption database 2008 (HITRAN08; Rothman et al., 2009), comprising spectroscopic parameters for every trace species absorption line, such as the transition frequencies of absorption line peaks, the line intensity, and air- and self-broadened half widths, plus estimated uncertainties of these parameters. We cross-checked 
Table 4. Absorption line center frequencies and corresponding reference frequency allocations used in the retrieval, complemented by information on spectroscopic parameter uncertainties from HITRAN08 for the two most relevant line parameters, line intensity and airbroadened half width.

\begin{tabular}{lccrcc}
\hline Species peak ID & $\begin{array}{c}\text { Abs. line } \\
{\left[\mathrm{cm}^{-1}\right]}\end{array}$ & $\begin{array}{r}\text { Ref. line } \\
{\left[\mathrm{cm}^{-1}\right]}\end{array}$ & $\begin{array}{r}\Delta(\text { Abs-Ref }) \\
{\left[\mathrm{cm}^{-1}\right]}\end{array}$ & $\begin{array}{c}\Delta \mathrm{S} \\
{[\%]}\end{array}$ & $\begin{array}{c}\Delta \gamma_{\text {air }} \\
{[\%]}\end{array}$ \\
\hline${ }^{12} \mathrm{CO}_{2}-1$ & 4767.37 & 4767.20 & 0.17 & $\geq 10$ and $<20$ & $\geq 5$ and $<10$ \\
${ }^{12} \mathrm{CO}_{2}-2$ & 4772.63 & 4772.82 & -0.19 & $\geq 10$ and $<20$ & $\geq 5$ and $<10$ \\
${ }^{13} \mathrm{CO}_{2}-1$ & 4766.64 & 4766.40 & 0.24 & $\geq 10$ and $<20$ & $\geq 5$ and $<10$ \\
$\mathrm{C}^{18} \mathrm{OO}-1$ & 4767.04 & 4767.20 & -0.16 & $\geq 10$ and $<20$ & $\geq 5$ and $<10$ \\
$\mathrm{C}^{18} \mathrm{OO}-2$ & 4768.79 & 4768.90 & 0.11 & $\geq 10$ and $<20$ & $\geq 5$ and $<10$ \\
$\mathrm{C}^{18} \mathrm{OO}-3$ & 4770.53 & 4770.20 & 0.33 & $\geq 10$ and $<20$ & $\geq 5$ and $<10$ \\
$\mathrm{H}_{2} \mathrm{O}-1$ & 4768.40 & 4768.68 & -0.28 & $\geq 5$ and $<10$ & $<1$ \\
$\mathrm{H}_{2} \mathrm{O}-2$ & 4776.59 & 4776.75 & -0.16 & $\geq 5$ and $<10$ & $\geq 1$ and $<2$ \\
$\mathrm{CH}_{4}-1$ & 4346.73 & 4346.95 & -0.22 & $\geq 2$ and $<5$ & $\geq 20$ \\
$\mathrm{CH}_{4}-2$ & 4348.16 & 4348.33 & -0.17 & $\geq 2$ and $<5$ & $\geq 2$ and $<5$ \\
\hline
\end{tabular}

the more recent HITRAN 2012 database (Rothman et al., 2013) and found that any changes are small for our wave number ranges of interest and would not lead to any relevant changes in results. We therefore kept using the HITRAN08 database, which was also used by Betal2012.

As a simple model for expected GHG concentrations, we invoked the Fast Atmospheric Signature Code model (FASCODE, 2008). More specifically, we adopted a basic set of volume mixing ratios $\mathcal{V}$ for four GHGs, namely $380 \mathrm{ppmv}$ of $\mathrm{CO}_{2}, 1.7 \mathrm{ppmv}$ of $\mathrm{CH}_{4}, 0.32 \mathrm{ppmv}$ of $\mathrm{N}_{2} \mathrm{O}$, and $0.13 \mathrm{ppmv}$ of $\mathrm{CO}$, all assumed to be homogeneously mixed in the atmosphere, i.e., with no volume mixing ratio changes in the ray path domain. For $\mathrm{H}_{2} \mathrm{O}$, we used the variable concentrations from the ECMWF analysis fields, and pressure and temperature were also taken from these fields.

\subsubsection{Absorption and reference line allocation}

The first important step was to find adequate absorption lines of GHGs in the available IR-laser-scanned spectral regions for the following set of GHGs: $X=\left\{{ }^{12} \mathrm{CO}_{2},{ }^{13} \mathrm{CO}_{2}, \mathrm{C}^{18} \mathrm{OO}\right.$, $\mathrm{CH}_{4} \mathrm{H}_{2} \mathrm{O}$ \}. The last two are meant to be the main isotopes of methane and water vapor. All isotopes of a GHG make up a certain ratio of the total concentration of this GHG, with the isotopic abundance factors taken from HITRAN08. Given all the uncertainties involved in this basic IR-laser demonstration experiment (discussed further below), more recent factors or more refined mole fraction values are not needed.

The set $X$ of GHGs and the corresponding absorption line center frequencies, plus the chosen reference frequencies, are listed in Table 4. We selected 10 usable absorption lines, including 2 for ${ }^{12} \mathrm{CO}_{2}, 1$ for ${ }^{13} \mathrm{CO}_{2}, 3$ for $\mathrm{C}^{18} \mathrm{OO}, 2$ for $\mathrm{H}_{2} \mathrm{O}$, and 2 for $\mathrm{CH}_{4}$. In order to avoid broadband effects, the reference frequencies are selected close by, as in the satellitebased IR-laser occultation concept, within a spectral distance of $0.15-0.35 \mathrm{~cm}^{-1}$. The rightmost two columns of Table 4 additionally show the HITRAN08 uncertainty estimates of the two spectroscopic parameters found to be of primary relevance to the overall uncertainty in our context here, the line intensity uncertainty $\Delta S$ and the air-broadened half-width uncertainty $\Delta \gamma_{\text {air }}$. The impact of these two (considerable) uncertainties will be discussed in Sect. 4 .

In Fig. 4 we illustrate a subset of simulated and measured IR-laser link transmission spectra to facilitate the understanding of the spectral characteristics and the measurement conditions. Individual absorption contributions of the targeted GHGs are well distinguished, as is the spectral broadening of the measured spectra, which is due to suboptimal detector gain settings during the spectral scanning. A high gain setting was necessary due to the strong atmospheric losses (in particular from beam divergence and molecular absorption), which limited the bandwidth and thus the response of the detector to rapid changes in laser power (for more technical detail see Betal2012; correction of this broadening for our purpose is discussed below).

The simulated total transmission spectra take all GHGs of set $X$ into account, in addition to the absorption due to $\mathrm{N}_{2} \mathrm{O}$ and CO. However, these two GHGs are found to have no relevant absorption contribution within the wave number ranges of interest; potential influences of such foreign GHGs on the absorption and reference channel transmissions will be discussed in Sect. 4. The chosen pairs of absorption and reference channels, marked by dotted lines, evidently fulfill well the requirements for the IR-laser occultation differential transmission principle and therefore allow the basic demonstration of this principle based on the long-path interisland transmission data. It is evident that a correction for the suboptimal-detector-gain-related spectral broadening of the measured spectra will be needed, which will add also to the uncertainty budget.

The bottom panel of Fig. 4 illustrates that the $\mathrm{CH}_{4}$ measurements by laser L3 in the $4346-4349 \mathrm{~cm}^{-1}$ wave number range suffered increased signal-to-noise ratio problems, as described by Betal2012. The retrieval of $\mathrm{CH}_{4}$ therefore 

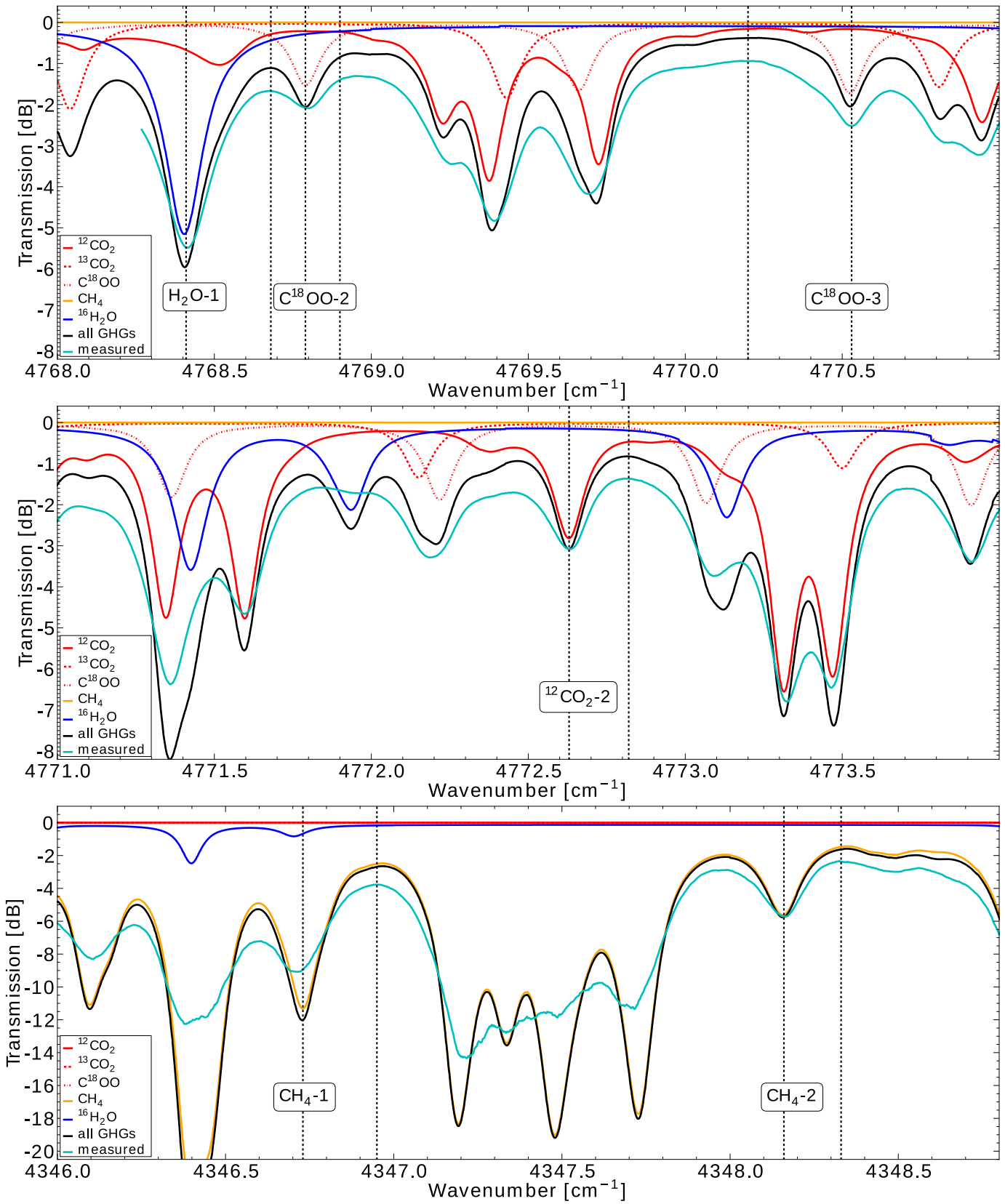

Figure 4. Examples of simulated transmission spectra of targeted GHG isotopes (see in-panel legends; for $\mathrm{H}_{2} \mathrm{O}$ and $\mathrm{CH}_{4}$ the main isotopes are utilized), of corresponding total transmission spectra from all GHGs (black curves), and of associated measured spectra (cyan curves). The respective absorption line center frequencies and nearby reference frequencies, according to Table 4, are marked by dash-dotted vertical lines, and the corresponding target GHGs are noted below the respective absorption line peaks. Three example wave number ranges are illustrated: one containing lines for $\mathrm{H}_{2} \mathrm{O}-1, \mathrm{C}^{18} \mathrm{OO}-2$, and $\mathrm{C}^{18} \mathrm{OO}-3$ (top panel); one for ${ }^{12} \mathrm{CO}_{2}-2$ (middle panel); and the two lines chosen for $\mathrm{CH}_{4}$ (bottom panel). The transmission alignment of the measured and simulated spectra is done in these panels for the $\mathrm{C}^{18} \mathrm{OO}_{-2},{ }^{12} \mathrm{CO}_{2}-2$ and $\mathrm{CH}_{4}-2$ absorption peaks, respectively.

needs to be expected to be of degraded quality compared to the $\mathrm{CO}_{2}$ isotope retrievals.

In the spectra of Fig. 4 we can furthermore clearly see the broadband contribution of all GHGs to the total absorption and reference channel transmissions of a targeted GHG.
However, since we employ the differential transmission principle, the influence of this broadband foreign GHG absorption on the retrieval accuracy is in practice weak or even negligibly small. 
An example is the weak influence of $\mathrm{H}_{2} \mathrm{O}$ on the ${ }^{12} \mathrm{CO}_{2}-2$ channels (middle panel) such that the fairly uncertain $\mathrm{H}_{2} \mathrm{O}$ concentration need not be simulated accurately in this case. On the other hand, an example for a noticeable influence is provided by the two $\mathrm{C}^{18} \mathrm{OO}-2$ channels (top panel); the adjacent $\mathrm{H}_{2} \mathrm{O}-1$ absorption line will leave some residual error in the differential transmission of the $\mathrm{C}^{18} \mathrm{OO}-2$ absorptionreference channel pair. Careful quantification and effective correction of such foreign GHG influences in the selfcalibrating IR-laser occultation retrieval procedure have been worked out by Schweitzer et al. (2011a) and Proschek et al. (2011). In the context of the experiment data analysis presented here, the quantification of such influences on the retrieval results will be given in Sect. 4.

\subsubsection{Spectral broadening correction}

The above-mentioned experiment-specific fact of suboptimal detector gain settings while scanning and recording the spectra (Betal2012, details in Appendix A5 therein) led to some artificial broadening of the measured spectral lines, as could already be seen in Fig. 4 and as is more specifically shown in Fig. 5 for three example GHG absorption lines.

In aligning measured and forward-modeled (simulated) transmissions at the absorption channel, the broadening in the measured spectrum becomes visible in the form of a decreased differential transmission between absorption and reference channel in comparison to the forward-modeled spectrum; this difference is marked in Fig. 5 as $\Delta \mathcal{T}_{\mathrm{SC}}$ and serves as a spectral correction term in the retrieval to achieve a proper match of forward-modeled and measured differential transmissions. In other words, $\Delta \mathcal{T}_{\mathrm{SC}}$ compensates for the suboptimal detector gain settings during acquisition of the IR-laser link data files (Table 2) in the course of the experiment. We emphasize that in actual IR-laser occultation measurements such a correction term would not occur; it is just an inadvertent additional effect of this first demonstration experiment (Betal2012).

The spectral correction term $\Delta \mathcal{T}_{\mathrm{SC}}$ clearly needs to be taken into account in the retrieval process of the campaign data, as it would otherwise bias the GHG results. In order to practically determine $\Delta \mathcal{T}_{\mathrm{SC}}$ for the chosen absorption lines (Table 4), we applied a box-car moving average filter to the forward-modeled (simulated) spectra such that the resulting filtered and therefore broadened simulated absorption line best matches the measured absorption line of interest. The difference between the original simulated transmission and the filtered-simulated transmission at the reference channel then determines the spectral correction term, as marked in the panels of Fig. 5.

For example, for the $\mathrm{C}^{18} \mathrm{OO}-2$ absorption line (upper panel of Fig. 5) a $\Delta \mathcal{T}_{\text {SC }}$ of $\sim 0.33 \mathrm{~dB}$ is estimated, which results from best matching the $\mathrm{C}^{18} \mathrm{OO}-2$ absorption line of a measured spectrum, randomly drawn from the subset of measured $4 \mathrm{~s}$ spectra (gray lines) in a given IR-laser link data file, by the broadened $\mathrm{C}^{18} \mathrm{OO}-2$ absorption line of the filteredsimulated spectrum. Different absorption lines in different IR-laser link data files (where adjustments of measurement settings may have occurred between acquisitions) may have received different broadening and therefore can lead to different correction terms $\Delta \mathcal{T}_{\mathrm{SC}}$ as is also illustrated by the different panels in Fig. 5.

In practice, the estimation and application of a specific spectral correction term was necessary for all IR-laser link data files and all chosen absorption lines, not only because of the changing measurement settings but also because of the broadband wave number ranges where the broadening of absorption lines was uneven over the scanned range (for technical details on data acquisition and raw spectra, wavelength calibration, and detector gain and offset issues see Betal2012, Appendix A therein). Table 5 lists all applicable spectral correction terms $\Delta \mathcal{T}_{\mathrm{SC}}$ determined for the 19 available data files (Table 2) and the 10 chosen absorption lines (Table 4).

The elaborate matching analysis of filtered-simulated and measured spectra, accompanied by comprehensive sensitivity tests for rough but robust estimation of uncertainties, revealed a reasonable systematic behavior of the spectral broadening effects in the different IR-laser link data files and their different lasers and wave number scan ranges. The different $\Delta \mathcal{T}_{\text {SC }}$ values result from the inadvertent broadening process due to detector gain issues having influenced narrow and deep absorption lines in a stronger way than broad and shallow lines. In addition, this "natural" behavior of the filtering can be somewhat perturbed by close neighbor absorption lines as well as near the margins of the scanned wavelength ranges.

In general, as Table 5 shows, the correction terms $\Delta \mathcal{T}_{\text {SC }}$ appear to be stable over data file acquisitions with the same lasers and the same wavelength scan ranges, i.e., when the measurement settings evidently have been (largely) the same. A good example is the files F2-F4 and F13-F16, regarding the three $\mathrm{CO}_{2}$ isotope absorption lines scanned by laser $\mathrm{L} 2$ (first three species columns) as well as the ${ }^{12} \mathrm{CO}_{2}$ absorption line scanned by laser L1 (seventh species column).

Other data files show similar patterns, also those including narrow wave number scan ranges that support a single absorption line only with each given laser, such as files F7-F10 (cf. Table 2). The $\Delta \mathcal{T}_{\mathrm{SC}}$ uncertainties listed in the caption of Table 5 have been estimated from the spread of the $\Delta \mathcal{T}_{\mathrm{SC}}$ values obtained from using the many individual $4 \mathrm{~s}$ spectra in the various data files.

As a specific case, the $\mathrm{CH}_{4}-1 \mid 2$ correction term values of 1.6 and $0.6 \mathrm{~dB}$ were found to be fairly high, given the narrowness and depth of the respective absorption lines. This is because of the quality of the two $\mathrm{CH}_{4}$ data files taken towards the very end of the campaign (files F18 and F19), which is clearly degraded compared to all other data files as mentioned above and as reported by Betal2012. Therefore, the $\mathrm{CH}_{4}$ retrieval results have to be treated with caution. More discussion about uncertainty margins follows in Sect. 4.1. 

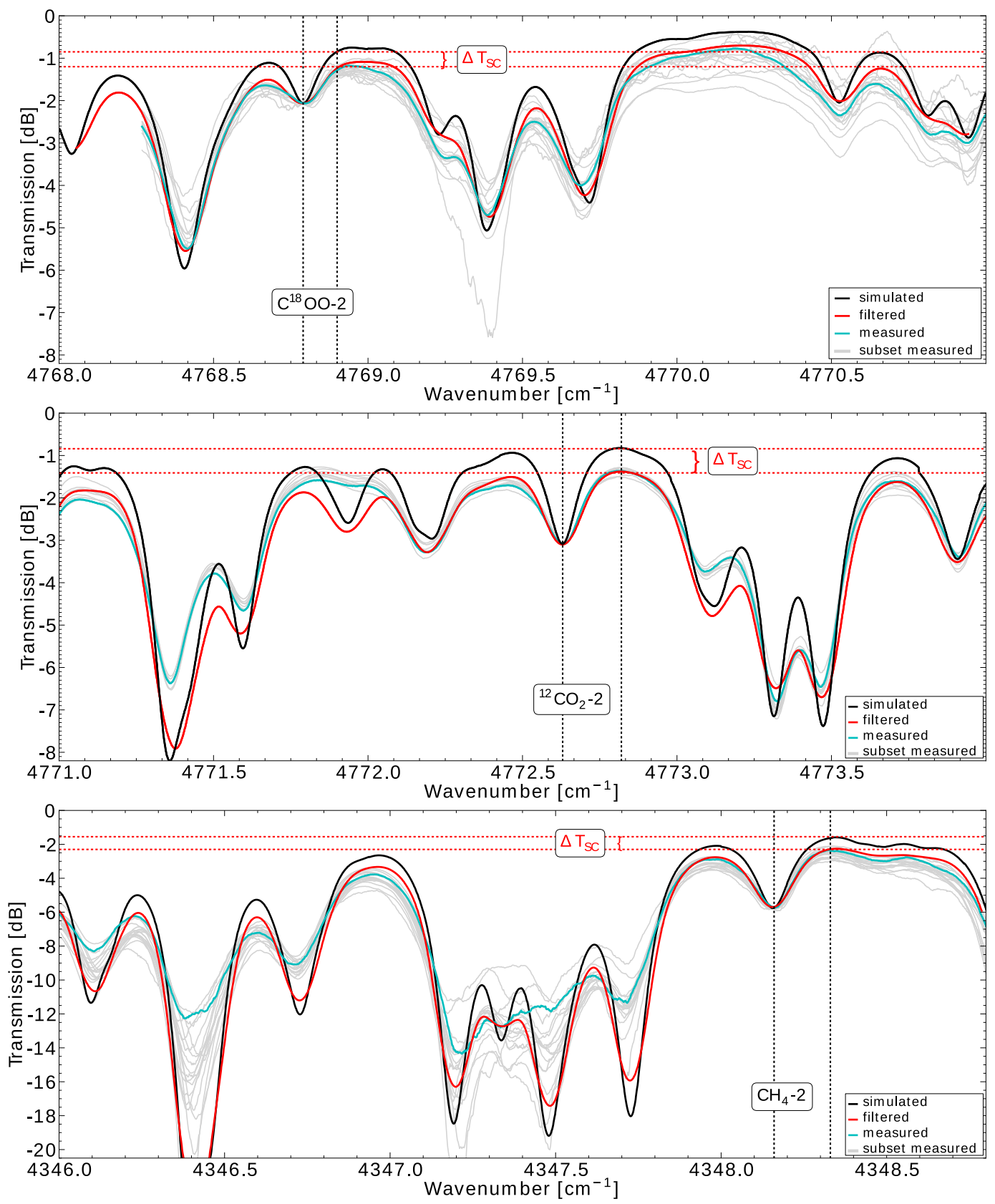

Figure 5. Examples of simulated spectra (black), filtered-simulated spectra (red), and measured spectra (cyan) from a typical set of measured spectra (gray), illustrating the spectral broadening, are aligned and marked in the same way as in Fig. 4. The wave number ranges illustrated in the three panels are the same as in Fig. 4, and the absorption lines illustrating the spectral broadening correction are marked in the same way as in Fig. 4. $\Delta \mathcal{T}_{\mathrm{SC}}$ marks the increment of differential transmission that is missing due to the line broadening in the measured data and that is therefore to be corrected for. The bundle of measured spectra shown in gray illustrates that any correction term $\Delta \mathcal{T}_{\mathrm{SC}}$ will also bring in some added uncertainty.

\subsection{Retrieval algorithm}

The aim of the GHG retrieval in this study is to demonstrate the differential transmission principle, which is the core of the IR-laser occultation processing part of the LMIO method (e.g., Proschek et al., 2011). Therefore, no full spectral fit of the forward-modeled spectra to the measured spectra is used, as was done in the initial evaluation of Betal2012, but the absorption-reference channel pairs for 10 suitable absorption lines, as listed in Table 4, are exploited. Recall that a spaceborne LMIO occultation method, which provides a very fast vertical scan through the atmosphere during an occultation 
Table 5. Spectral correction terms $\Delta \mathcal{T}_{\mathrm{SC}}$ estimated for the 10 chosen GHG absorption lines of the 19 IR-laser link data files available for retrieval processing. An uncertainty of $\pm 0.1 \mathrm{~dB}$ was co-estimated for the $\Delta \mathcal{T}_{\mathrm{SC}}$ best-estimate values of $0.79,0.59$ and 0.53 , of $\pm 0.09 \mathrm{~dB}$ for 0.49 , of $\pm 0.08 \mathrm{~dB}$ for 0.33 and 0.23 , and of $\pm 0.07 \mathrm{~dB}$ for 0.13 , respectively. The $\mathrm{CH}_{4} \Delta \mathcal{T}_{\text {SC }}$ values were estimated as 1.6 and 0.6 , with an uncertainty of $\pm 0.13 \mathrm{~dB}$. The numbers in bold represent the measurements with laser L1, and the upright numbers those with laser L2; the $\mathrm{CH}_{4}$ measurements were performed with laser L3.

\begin{tabular}{|c|c|c|c|c|c|c|c|c|c|c|}
\hline \multirow{2}{*}{$\begin{array}{l}\text { File } \\
\text { no. }\end{array}$} & \multicolumn{10}{|c|}{ Spectral correction term $\left(\Delta \mathcal{T}_{\mathrm{SC}}\right)[\mathrm{dB}]$} \\
\hline & ${ }^{13} \mathrm{CO}_{2-1}$ & $\mathrm{C}^{18} \mathrm{OO}-1$ & ${ }^{12} \mathrm{CO}_{2-1}$ & $\mathrm{H}_{2} \mathrm{O}-1$ & $\mathrm{C}^{18} \mathrm{OO}-2$ & $\mathrm{C}^{18} \mathrm{OO}-3$ & ${ }^{12} \mathrm{CO}_{2-2}$ & $\mathrm{H}_{2} \mathrm{O}-2$ & $\mathrm{CH}_{4}-1$ & $\mathrm{CH}_{4}-2$ \\
\hline F1 & $\mathrm{x}$ & $\mathrm{x}$ & $\mathrm{x}$ & 0.59 & $\mathrm{x}$ & $\mathrm{x}$ & $\mathrm{x}$ & $\mathrm{x}$ & $\mathrm{x}$ & $\mathrm{x}$ \\
\hline $\mathrm{F} 2$ & 0.79 & 0.33 & 0.53 & $\mathrm{x}$ & $\mathrm{x}$ & $\mathrm{x}$ & 0.59 & $\mathrm{x}$ & $\mathrm{x}$ & $\mathrm{x}$ \\
\hline F3 & 0.79 & 0.33 & 0.53 & $\mathrm{x}$ & $\mathrm{x}$ & $\mathrm{x}$ & 0.59 & $\mathrm{x}$ & $\mathrm{x}$ & $\mathrm{x}$ \\
\hline F4 & 0.79 & 0.33 & 0.53 & $\mathrm{x}$ & $\mathrm{x}$ & $\mathrm{x}$ & 0.59 & $\mathrm{x}$ & $\mathrm{x}$ & $\mathrm{x}$ \\
\hline F5 & $\mathrm{x}$ & $\mathrm{x}$ & $\mathrm{x}$ & $\mathrm{x}$ & 0.33 & $\mathrm{x}$ & $\mathrm{X}$ & $\mathrm{x}$ & $\mathrm{x}$ & $\mathrm{x}$ \\
\hline F6 & 0.49 & 0.13 & 0.23 & 0.59 & 0.33 & 0.13 & $\mathrm{x}$ & $\mathrm{x}$ & $\mathrm{x}$ & $\mathrm{x}$ \\
\hline F7 & $\mathrm{x}$ & $\mathrm{x}$ & $\mathrm{x}$ & $\mathrm{x}$ & 0.23 & $\mathrm{x}$ & $\mathrm{x}$ & $\mathrm{x}$ & $\mathrm{x}$ & $\mathrm{x}$ \\
\hline F8 & $\mathrm{x}$ & $\mathrm{x}$ & $\mathrm{x}$ & $\mathrm{x}$ & 0.23 & $\mathrm{x}$ & $\mathrm{x}$ & $\mathrm{x}$ & $\mathrm{x}$ & $\mathrm{x}$ \\
\hline F9 & $\mathrm{x}$ & $\mathrm{x}$ & $\mathrm{x}$ & $\mathrm{x}$ & 0.23 & 0.33 & $\mathrm{x}$ & $\mathrm{x}$ & $\mathrm{x}$ & $\mathrm{x}$ \\
\hline F10 & $\mathrm{x}$ & $\mathrm{x}$ & $\mathrm{x}$ & $\mathrm{x}$ & 0.23 & 0.33 & $\mathrm{x}$ & $\mathrm{x}$ & $\mathrm{x}$ & $\mathrm{x}$ \\
\hline F11 & 0.59 & 0.23 & 0.33 & 0.59 & $\mathbf{0 . 3 3}$ & 0.13 & $\mathrm{x}$ & $\mathrm{x}$ & $\mathrm{x}$ & $\mathrm{x}$ \\
\hline F12 & 0.59 & 0.23 & 0.33 & 0.59 & 0.33 & 0.13 & $\mathrm{x}$ & $\mathrm{x}$ & $\mathrm{x}$ & $\mathrm{x}$ \\
\hline F13 & 0.79 & 0.33 & 0.53 & $\mathrm{x}$ & $\mathrm{x}$ & $\mathrm{x}$ & 0.59 & $\mathrm{x}$ & $\mathrm{x}$ & $\mathrm{x}$ \\
\hline F14 & 0.79 & 0.33 & 0.53 & $\mathrm{x}$ & $\mathrm{x}$ & $\mathrm{x}$ & 0.59 & $\mathrm{X}$ & $\mathrm{x}$ & $\mathrm{x}$ \\
\hline F15 & 0.79 & 0.33 & 0.53 & $\mathrm{x}$ & $\mathrm{x}$ & $\mathrm{x}$ & $\mathrm{x}$ & 0.33 & $\mathrm{x}$ & $\mathrm{x}$ \\
\hline F16 & 0.79 & 0.33 & 0.53 & $\mathrm{x}$ & $\mathrm{x}$ & $\mathrm{x}$ & $\mathrm{x}$ & $\mathbf{0 . 3 3}$ & $\mathrm{x}$ & $\mathrm{x}$ \\
\hline F17 & $\mathrm{x}$ & $\mathrm{X}$ & $\mathrm{X}$ & $\mathrm{X}$ & $\mathrm{x}$ & $\mathrm{x}$ & $\mathrm{x}$ & $\mathrm{X}$ & $\mathrm{X}$ & $\mathrm{x}$ \\
\hline F18 & $\mathrm{x}$ & $\mathrm{x}$ & $\mathrm{x}$ & $\mathrm{x}$ & $\mathrm{x}$ & $\mathrm{x}$ & $\mathrm{x}$ & $\mathrm{x}$ & 1.6 & $\mathrm{X}$ \\
\hline F19 & $\mathrm{x}$ & $\mathrm{x}$ & $\mathrm{x}$ & $\mathrm{x}$ & $\mathrm{x}$ & $\mathrm{x}$ & $\mathrm{x}$ & $\mathrm{x}$ & $\mathrm{x}$ & 0.6 \\
\hline
\end{tabular}

event, would not provide spectra but rather accurately measured "monochromatic" data for selected absorption and reference channels (Kirchengast and Schweitzer, 2011).

Given the limited accuracy of the wavemeter and the wavelength calibration in the experiment (Betal2012), the absorption line center frequencies of the campaign data do fairly well but not exactly match the nominal line center wave number values according to Table 4 . The first step of the retrieval was therefore, for each chosen absorption line, to search in the measured spectra at the Rx site for the wave number of the peak of the targeted absorption line, starting from the nominal wave number of the simulated absorption line center, and to extract the corresponding signal amplitude in the Tx and Rx signal, $\mathcal{A}_{\mathrm{Abs}, \mathrm{Tx}}$ and $\mathcal{A}_{\mathrm{Abs}, \mathrm{Rx}}$.

This was followed by the search for the associated reference channel wave number, chosen to be the wave number of minimum absorption in the nominal wave number interval between the respective reference and absorption channel (cf. Table 4), and by extracting at this wave number the corresponding signal amplitude, $\mathcal{A}_{\text {Ref,Tx }}$ and $\mathcal{A}_{\text {Ref,Rx}}$. Typically, these minimum-absorption wave numbers were found just near the nominal reference wave numbers since the nominal wave numbers had been selected to approximately correspond to the first absorption minimum ("valley") adjacent to the targeted absorption line maximum ("peak") (cf. Fig. 5).
The signal amplitude and wave number values (close to the nominal values) extracted in this way were used in the further retrieval procedure. The relative amplitude $\mathcal{A}$ values, available in units $[\mathrm{V} / \mathrm{V}]$ in the data files, were converted into units $[\mathrm{dB}]$ and used to determine the measured differential transmission for any targeted absorption line, $\Delta \mathcal{T}_{\text {tgt,Meas }}$, in the form

$\Delta \mathcal{T}_{\text {tgt,Meas }}=\left[\mathcal{A}_{\mathrm{Abs}, \mathrm{Rx}}-\mathcal{A}_{\mathrm{Abs}, \mathrm{Tx}}\right]-\left[\mathcal{A}_{\mathrm{Ref}, \mathrm{Rx}}-\mathcal{A}_{\mathrm{Ref}, \mathrm{Tx}}\right]$.

The corresponding simulated differential transmissions, $\Delta \mathcal{T}_{\text {tgt,Sim }}$, computed at the wave numbers determined above (doing so at the nominal wave numbers would not appreciably change the results), were prepared to match these measured transmissions. This was done by employing the RFM model (Dudhia, 2008) within an iterative process to finally determine the desired volume mixing ratios of the target GHGs. The algorithm works as follows.

As a first step, a 3-D ray tracing from the Tx site to Rx site is performed, to determine ray path coordinates in densely sampled along-ray steps (100 $\mathrm{m}$ spacing). Within this process, the refractivity is calculated by use of the modified Edlén formula, which was also applied by Proschek et al. (2011). The atmospheric conditions along the ray are taken from the ECMWF analysis fields, interpolated to the start time of any data file for all spectra in the file. Sensitivity tests showed that there was no need to repeatedly compute 
the ray path for $4 \mathrm{~s}$ spectra individually since the variations in pressure $(p)$ and temperature $(T)$ are very small over the short time frame of a data file, such that the initial ray path does not change appreciably (for more information on the estimated uncertainty in $p$ and $T$ themselves see Sects. 2.2, and 4.4). The ECMWF values of $p, T$, and $\mathrm{H}_{2} \mathrm{O}$ (derived from the humidity) obtained along the ray path were then stored for later usage in the iterative GHG retrieval, which was done for all $4 \mathrm{~s}$ spectra of a file.

The iterative retrieval needs reasonable initial values for the targeted GHGs as well as for some background GHGs that may have a small influence on the selected absorption and reference channels. We chose the along-ray-averaged $\mathrm{H}_{2} \mathrm{O}$ value from ECMWF as the initial/background value for $\mathrm{H}_{2} \mathrm{O}$, and the $\mathrm{CO}_{2}, \mathrm{CH}_{4}, \mathrm{~N}_{2} \mathrm{O}$, and $\mathrm{CO}$ values from FASCODE (FASCODE, 2008), as quoted in Sect. 2, as initial/background values for these well-mixed GHGs. The foreign-species influence of $\mathrm{CO}$ is only relevant to $\mathrm{CH}_{4}$ and and very small (transmission affected within $0.01 \mathrm{~dB}$ ), so the somewhat less well mixed character of this species is not relevant here and we can as well use the fixed FASCODE value for its initialization. All target GHGs, determined as ray-path-averaged volume mixing ratios $\overline{\mathcal{V}}_{\text {tgt }}$, are utilized in units of parts per million by volume (ppmv).

The iteration process uses the atmospheric parameters and initial/background GHG values and - for any chosen GHG absorption line (Table 4) in a data file - includes at each iteration step $i$ the simulation of along-ray transmissions for absorption and reference channel, $\mathcal{T}_{\mathrm{Abs}, \mathrm{Sim} ; i}$ and $\mathcal{T}_{\mathrm{Ref}, \mathrm{Sim} ; i}$, as well as of the ray-averaged absorption cross section, $\bar{\sigma}_{\text {tgt }}$, employing the RFM model (Dudhia, 2008). The iteration itself is a simple and robust Newton iteration over target GHG volume mixing ratio, $\overline{\mathcal{V}}_{\text {tgt; } i}$, starting with an initial value $\overline{\mathcal{V}}_{\text {tgt; } 0}$ and being iteratively updated proportional to a residual differential transmission increment $\Delta\left[\Delta \mathcal{T}_{\text {tgt; } i}\right]$. In particular, the algorithm is formulated as

$\overline{\mathcal{V}}_{\mathrm{tgt} ; i+1}=\overline{\mathcal{V}}_{\mathrm{tgt} ; i}-\frac{c_{\mathrm{dB} 2 \%} \cdot \mathcal{R} \cdot \bar{T} \cdot \Delta\left[\Delta \mathcal{T}_{\mathrm{tgt} ; i}\right]}{\bar{p} \cdot \bar{\sigma}_{\mathrm{tgt}}\left(\bar{T}, \bar{p}, \overline{\mathcal{V}}_{\mathrm{tgt} ; i}\right) \cdot L_{\mathrm{TxRx}}}$,

where

$\Delta\left[\Delta \mathcal{T}_{\text {tgt } ; i}\right]=\Delta \mathcal{T}_{\text {tgt,Sim } ; i}-\Delta \mathcal{T}_{\text {tgt,Meas }}$,

with

$$
\begin{aligned}
\Delta \mathcal{T}_{\mathrm{tgt}, \mathrm{Sim} ; i} & =\mathcal{T}_{\mathrm{Abs}, \operatorname{Sim} ; i}\left(T, p, \overline{\mathcal{V}}_{\mathrm{tgt} ; i}\right) \\
& -\mathcal{T}_{\mathrm{Ref}, \operatorname{Sim} ; i}\left(T, p, \overline{\mathcal{V}}_{\mathrm{tgt} ; i}\right)-\Delta \mathcal{T}_{\mathrm{SC}, \mathrm{tgt}}
\end{aligned}
$$

In this set of equations, $\Delta \mathcal{T}_{\mathrm{SC} \text {,tgt }}$ (in $\mathrm{dB}$ ) is the spectral correction term that accounts for the spectral broadening explained in Sect. 3.1.2. It enables the simulated target GHG differential transmission $\Delta \mathcal{T}_{\text {tgt,Sim; } i}$ (in dB) to nominally match the measured differential transmission $\Delta \mathcal{T}_{\text {tgt,Meas }}$ (in $\mathrm{dB}$ ), in order to produce an adequate residual increment
$\Delta\left[\Delta \mathcal{T}_{\text {tgt;i}}\right]$ (in $\mathrm{dB}$ ). $\bar{T}$ (in $\mathrm{K}$ ) and $\bar{p}$ (in $\mathrm{Pa}$ ) are the rayaveraged temperature and pressure, respectively, $c_{\mathrm{dB} 2 \%}=$ $23.026 \% \mathrm{~dB}^{-1}$ is the conversion factor from units $\mathrm{dB}$ to units $\%, \mathcal{R}=8.3145 \mathrm{~J} \mathrm{~K}^{-1} \mathrm{~mol}^{-1}$ is the molar gas constant, $\bar{\sigma}_{\text {tgt }}$ (in $\mathrm{m}^{2} \mathrm{~mol}^{-1}$ ) is the target GHG molar cross section at the absorption line center, and $L_{\mathrm{TxRx}}$ (in $\mathrm{m}$ ) is the ray path length from Tx to Rx.

We found that this iterative algorithm converges fast within a few iterations (seven at most); we terminated it when the residual relative change in the volume mixing ratio, $100 \cdot \frac{\left|\overline{\mathcal{V}}_{\mathrm{tgt} ; i+1}-\overline{\mathcal{V}}_{\mathrm{tgt} ; i}\right|}{\overline{\mathcal{V}}_{\mathrm{tgt} ; i}}$, was smaller than $0.05 \%$ or when $10 \mathrm{it}-$ eration steps did not lead to convergence (the latter occurred only in rare cases of problematic spectra, however, for which the results generally ended as outliers). The final iteration results for $\overline{\mathcal{V}}_{\text {tgt }}$ were stored as the retrieved GHG values. They are discussed in terms of their uncertainty and their consistency with the independent validation data in the next sections.

\section{Retrieval uncertainty analysis}

We now discuss the uncertainties estimated for the retrieval results, the GHG volume mixing ratios $\mathcal{V}$, and their different origins. There are several influences which are of a mixed systematic and random nature. Table 6 lists all of them for the 10 selected absorption species peaks. The estimated uncertainties $\Delta \mathcal{V}$ include uncertainties due to the limited accuracy of the spectral correction term $\Delta \mathcal{T}_{\mathrm{SC}}$ and of the spectroscopic parameters as well as due to the limited knowledge of atmospheric water vapor $\left(\mathrm{H}_{2} \mathrm{O}\right)$ concentration and of pressure and temperature (Table 6). The underlying sources of these four types of uncertainty are essentially independent, so the resulting combined uncertainty can be computed as a root-mean-square sum of the four uncertainties.

The combined uncertainties (rightmost column of Table 6) for the $\mathrm{CO}_{2}$ isotopes amount to about 11-14\% and are dominated by the spectroscopic uncertainties. For comparison, the initial example $\mathrm{CO}_{2}$ retrieval performed by Betal2012 led to an uncertainty estimate of about $4 \%$, but this value included neither the spectroscopic uncertainty (even if it was discussed in the text) nor the spectral-correction-term uncertainty (as they did a spectral-fit retrieval rather than a differential transmission retrieval from absorption-reference channel pairs). If we excluded these two uncertainty sources, the current uncertainty estimate from our differential transmission retrieval process would still be somewhat more conservative (about $6 \%$ ), since we found somewhat higher values for the uncertainties due to $\mathrm{H}_{2} \mathrm{O}$ concentration, $p$, and $T$ from our more detailed analysis.

The combined $\mathrm{H}_{2} \mathrm{O}$ uncertainty is about $51 \%$, strongly governed by the uncertain $\mathrm{H}_{2} \mathrm{O}$ knowledge from the validation data. Finally, the combined $\mathrm{CH}_{4}-1$ uncertainty is about $22 \%$, dominated by spectroscopic uncertainty, while 
Table 6. Estimated uncertainties $\Delta \mathcal{V}$ in retrieved GHG volume mixing ratios $\mathcal{V}$, for the 10 selected species absorption lines. The estimates include uncertainties in $\mathcal{V}$ due to spectral-correction-term uncertainty, spectroscopic uncertainty, water vapor uncertainty, and pressure and temperature uncertainty. The resulting combined uncertainty is shown as well.

\begin{tabular}{lccccc}
\hline Species peak ID & $\begin{array}{c}\Delta \mathcal{T}_{\text {SC }} \text { uncert. } \\
\pm \Delta \mathcal{V}[\%]\end{array}$ & $\begin{array}{c}\text { Spectr. uncert. } \\
\pm \Delta \mathcal{V}[\%]\end{array}$ & $\begin{array}{c}\mathrm{H}_{2} \mathrm{O} \text { uncert. } \\
\pm \Delta \mathcal{V}[\%]\end{array}$ & $\begin{array}{c}p, T \text { uncert. } \\
\pm \Delta \mathcal{V}[\%]\end{array}$ & $\begin{array}{c}\text { Combined uncert. } \\
\pm \Delta \mathcal{V}[\%]\end{array}$ \\
\hline${ }^{12} \mathrm{CO}_{2}-1$ & 4.6 & 10 & 2.3 & 6.0 & 12.7 \\
${ }^{12} \mathrm{CO}_{2}-2$ & 4.4 & 10 & 0.5 & 6.0 & 12.5 \\
${ }^{13} \mathrm{CO}_{2}-1$ & 4.5 & 10 & 1.5 & 0.5 & 11.1 \\
$\mathrm{C}^{18} \mathrm{OO}-1$ & 8.2 & 10 & 6.0 & 1.0 & 14.3 \\
$\mathrm{C}^{18} \mathrm{OO}-2$ & 7.6 & 10 & 4.0 & 1.0 & 13.2 \\
$\mathrm{C}^{18} \mathrm{OO}-3$ & 6.5 & 10 & 0.5 & 1.0 & 12.0 \\
$\mathrm{H}_{2} \mathrm{O}-1$ & 4 & 8 & 50 & 3.5 & 50.9 \\
$\mathrm{H}_{2} \mathrm{O}-2$ & 2 & 8 & 50 & 3.5 & 50.8 \\
$\mathrm{CH}_{4}-1$ & 8.4 & 20 & 4.3 & 1.0 & 22.1 \\
$\mathrm{CH}_{4}-2$ & 8.3 & 5 & 0.3 & 1.0 & 9.7 \\
\hline
\end{tabular}

the combined $\mathrm{CH}_{4}-2$ uncertainty is about $10 \%$, dominated by the uncertainty in the spectral correction term.

The individual uncertainty contributions are briefly explained separately in the following subsections, followed by a discussion of the complementary estimation of the statistical uncertainty from the measurements. The latter was estimated, within averaging periods of about $10 \mathrm{~min}$, based on the ensemble of retrieved GHG values (from the individual $4 \mathrm{~s}$ spectra) falling into each such period.

\subsection{Uncertainty due to the spectral correction term}

The uncertainty $\Delta \mathcal{V}$ in the spectral correction term takes into account the uncertainty transferred into the volume mixing ratio from the uncertainty (spread) of the $\Delta \mathcal{T}_{\mathrm{SC}}$ values obtained when best matching individual $4 \mathrm{~s}$ spectra within an IR-laser link data file to the corresponding filtered-simulated spectrum of the file. Details of the $\Delta \mathcal{T}_{\mathrm{SC}}$ estimation have been described in Sect. 3.1.2 above, and the best-estimate values and their corresponding uncertainties $\Delta\left(\Delta \mathcal{T}_{\mathrm{SC}}\right)$ have been listed in Table 5 and its caption. These uncertainties $\Delta\left(\Delta \mathcal{T}_{\mathrm{SC}}\right)$ are the basis for estimating the corresponding uncertainties $\Delta \mathcal{V}$ for all targeted absorption lines, shown in Table 6 .

The relation between $\Delta \mathcal{V}$ and $\Delta\left(\Delta \mathcal{T}_{\mathrm{SC}}\right)$ is essentially a linear one as visible from the right-hand-side term of Eq. (2) above, where one subterm within $\Delta\left(\Delta \mathcal{T}_{\text {tgt }}\right)$ is $\Delta\left(\Delta \mathcal{T}_{\text {SC }}\right)$. We used this right-hand-side term of Eq. (2) to estimate the linear transfer function from $\Delta\left(\Delta \mathcal{T}_{\mathrm{SC}}\right)$ to $\Delta \mathcal{V}$ for all species' absorption peaks. Figure 6 shows example results for $\mathrm{CO}_{2}$ isotope lines, where the linear solid lines indicate the relation that somewhat varies due to the different underlying atmospheric conditions and absorption cross sections of different spectra (spread of lines with same color). Cross-check with real GHG retrieval results based on Eqs. (2)-(4), using intentional relative changes $\Delta\left(\Delta \mathcal{T}_{\mathrm{SC}}\right)$ of $+20,+30$, and $+40 \%$

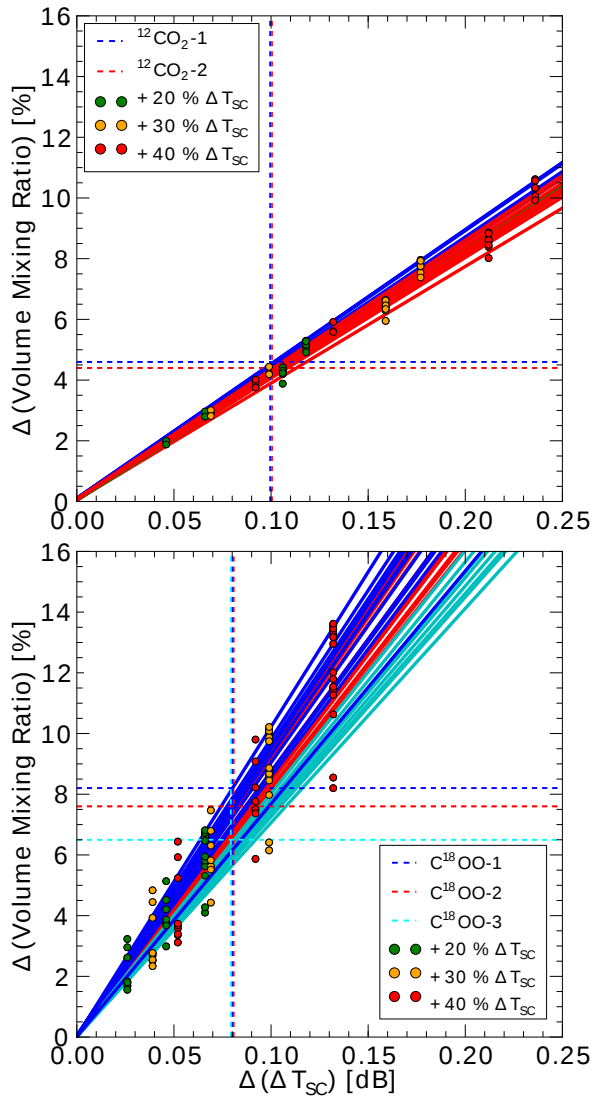

Figure 6. Examples for the linear dependence of volume mixing ratio uncertainty $\Delta(\mathcal{V})(\%)$ on spectral correction term uncertainty $\Delta\left(\Delta \mathcal{T}_{\mathrm{SC}}\right)(\mathrm{dB})$, for the ${ }^{12} \mathrm{CO}_{2}-1 \mid 2$ peaks (upper panel; blue and red) and the $\mathrm{C}^{18} \mathrm{OO}-1|2| 3$ peaks (lower panel; blue, red, cyan). The linear transfer functions (bundles of colored solid lines per species peak) and the cross-check results for the $\Delta(\mathcal{V})\left[\Delta\left(\Delta \mathcal{T}_{\mathrm{SC}}\right)\right]$ relation from actual retrieval (color-filled circles) are explained and discussed in Sect. 4.1. 
against the best-estimate $\Delta \mathcal{T}_{\mathrm{SC}}$, quite well confirmed the linear relation and the spread (color-filled circles in Fig. 6).

Therefore, we used these linear transfer functions to conservatively estimate $\Delta \mathcal{V}$ from $\Delta\left(\Delta \mathcal{T}_{\mathrm{SC}}\right)$, in the sense that we used, for any absorption peak of Table 6 , the highest applicable $\Delta\left(\Delta \mathcal{T}_{\mathrm{SC}}\right)$ value from the caption of Table 5 (vertical dotted lines in Fig. 6) and then estimated the corresponding $\Delta \mathcal{V}$ value to be the one associated with the steepest linear transfer function among the bundle of functions evaluated for a given peak (horizontal dotted lines in Fig. 6, indicating the resulting $\Delta \mathcal{V}$ on the $y$ axis).

The spectral-correction-term uncertainties summarized in Table 6 (second column) were all estimated in this way, and their typical range is from about 4 to $8 \%$. Clearly, a followon experiment should aim at avoiding this uncertainty component by optimized control and documentation of experiment settings and an improved signal-to-noise ratio at the receiver.

\subsection{Uncertainty due to spectroscopic parameters}

The uncertainty in the spectroscopic parameters is estimated on the basis of the uncertainties given by the HITRAN08 database (Rothman et al., 2009). The most relevant contributing uncertainties have been shown in Table 4 and include the uncertainty in the line intensity, $\Delta S$, and in the air-broadened half width, $\Delta \gamma_{\text {air }}$. Their contribution to the computation of simulated absorption lines can be seen from the detailed equations in Appendix A2 of Rothman et al. (1998), which shows that these two uncertainties dominate (see also the results of Harrison et al., 2011). We therefore use these two uncertainties $\Delta S$ and $\Delta \gamma_{\text {air }}$ as the basis for the spectroscopic uncertainty, which will also contribute to the combined volume mixing ratio uncertainty $\Delta \mathcal{V}$.

Based on the results of and experience from the sensitivity studies in Harrison et al. (2011), we assume a roughly linear relation between the spectroscopic uncertainty and $\Delta \mathcal{V}$, reflecting also that the uncertainties in line intensity and airbroadened half width generally do not add linearly but do partially compensate each other in $\Delta \mathcal{V}$. On the basis of these assumptions, we adopted as spectroscopic uncertainty estimates in Table 6 (third column) a reasonable trade-off value of the upper and lower margin uncertainty estimates from HITRAN08 according to Table 4.

In particular, for the $\mathrm{CO}_{2}$ isotopes we adopted an uncertainty of $10 \%$ (the $\Delta S$ lower and $\Delta \gamma_{\text {air }}$ upper margin), and for $\mathrm{H}_{2} \mathrm{O} 8 \%$ (near the $\Delta S$ upper margin, given that $\Delta \gamma_{\text {air }}$ is quoted to be accurate to within $1-2 \%$ for these lines in HITRAN08). For $\mathrm{CH}_{4}-1$ we adopted an uncertainty of $20 \%$ (dominated by the respective $\Delta \gamma_{\text {air }}$ uncertainty quoted in HITRAN08 to be at least $20 \%$ ) and for $\mathrm{CH}_{4}-25 \%$ (upper margin of $\Delta S$ and $\Delta \gamma_{\text {air }}$ for this line).

It is clear that these uncertainty estimates are educated guesses only rather than detailed quantitative estimates. However, given the coarseness of the uncertainty specifica- tions in HITRAN and the unknown sign of the errors in the spectroscopic parameters as well as the first-time nature of the IR-laser link experiment evaluated in this study, we do not consider it worthwhile to explore this uncertainty in a more refined manner for the current purpose. Rather we strongly recommend, underscoring the conclusions of Harrison et al. (2011), that the current spectroscopic knowledge on the selected lines for the "ACCURATE - climate benchmark profiling of greenhouse gases and thermodynamic variables and wind from space"/LMIO mission concept should be substantially improved by new highly accurate laboratory spectroscopy in order to meet the ACCURATE spectroscopic accuracy requirements (Kirchengast and Schweitzer, 2011; Harrison et al., 2011). As discussed by Harrison et al. (2011), this could reduce spectroscopic uncertainty in a follow-on experiment to smaller than $0.2 \%$.

\subsection{Uncertainty due to water vapor}

In Sect. 2.2 and Fig. 2 we showed that the water vapor volume mixing ratio in the CRDS validation data exhibited a comparatively small variation of $\sim 0.1 \%$ during the measurement times at the Rx site, while it varied from about 0.2 to $0.8 \%$ at the Tx site. Furthermore, the along-ray water vapor from ECMWF showed volume-mixing-ratio variations within about $0.1-0.5 \%$ (Fig. 3), which is comparable with the CRDS ranges. In order to account for these considerable variations, we adopted a large uncertainty of $\pm 50 \%$ regarding the knowledge of $\mathrm{H}_{2} \mathrm{O}$ along the IR-laser link (reflecting a " $2 \sigma$ range" from $<0.1$ to $0.6 \%$ when assuming a central value of $0.3 \%$, roughly covering the variability).

Table 6 (fourth column) shows that this limited knowledge available on $\mathrm{H}_{2} \mathrm{O}$ from the campaign (uncertainty $50 \%$ ) strongly governs the combined uncertainty conservatively attributed to the $\mathrm{H}_{2} \mathrm{O}$ volume mixing ratio. The validation for this highly variable species will therefore only allow for very broadly checking of the consistency of the retrieved data with the validation data.

On the other hand, despite the need to assume such a high uncertainty on the $\mathrm{H}_{2} \mathrm{O}$ volume mixing ratio, the absorption lines of the $\mathrm{CO}_{2}$ isotopes and of $\mathrm{CH}_{4}$ are found to be very weakly sensitive to this uncertainty, since the $\mathrm{H}_{2} \mathrm{O}$ foreignspecies influence on these absorption lines is very small (see Table 6 fourth column). Moreover, the effect of $\mathrm{H}_{2} \mathrm{O}$ on the IR refractivity is smaller than $0.1 \%$ (e.g., Schweitzer et al., 2011a), so the ray path knowledge is essentially not influenced by the $\mathrm{H}_{2} \mathrm{O}$ uncertainty either.

Retrieval computations for sensitivity testing that assume an $\mathrm{H}_{2} \mathrm{O}$ uncertainty of $\pm 50 \%$ confirm that the uncertainties $\Delta \mathcal{V}$ induced in retrieved $\mathrm{CO}_{2}$ isotopes and $\mathrm{CH}_{4}$ are generally in the range of about $0.5-4 \%$ only, much smaller than the spectral-correction-term and spectroscopic uncertainties. The estimates in Table 6 (fourth column) for the $\mathrm{CO}_{2}$ and $\mathrm{CH}_{4}$ lines are from such computations. The least-sensitive line is $\mathrm{CH}_{4}-2(0.3 \%)$, the most sensitive one $\mathrm{C}^{18} \mathrm{OO}-2(6 \%)$. 
The latter line well illustrates that the major source of this uncertainty is the residual differential foreign-species influence of $\mathrm{H}_{2} \mathrm{O}$ on the absorption and reference channels (compare the $\mathrm{H}_{2} \mathrm{O}$ spectrum in Fig. 4, upper panel, near the $\mathrm{C}^{18} \mathrm{OO}-2$ peak).

Related to a follow-on experiment we can learn from these uncertainty estimates that an effort to provide $\mathrm{H}_{2} \mathrm{O}$ validation data to within an accuracy of $5 \%$ (representative along the IR-laser link, e.g., from a co-aligned microwave link with suitable frequencies near $23 \mathrm{GHz}$, as part of the LMIO method; Schweitzer et al., 2011a) would enable this uncertainty component to be constrained to less than 0.2 and $0.5 \%$ in $\mathrm{CO}_{2}$ and $\mathrm{CH}_{4}$ retrievals, respectively. This reduction of uncertainty in $\mathrm{CO}_{2}$ and $\mathrm{CH}_{4}$ by an order of magnitude (from order $1 \%$ to order $0.1 \%$ ) would arise from the reduction of the $\mathrm{H}_{2} \mathrm{O}$ uncertainty from 50 to $5 \%$.

\subsection{Uncertainty due to pressure and temperature}

Since atmospheric pressure and temperature play a role in the ray path simulation and the iteration process to calculate $\mathcal{V}$ (Eqs. 2-4), the contribution of their measurement uncertainty, estimated to be $1 \%$ (see Sect. 2.2, Fig. 2), to the retrieval uncertainty $\Delta \mathcal{V}$ must also be investigated.

Regarding their influence on the ray path trajectory, we found that the effects of the $1 \%$ uncertainty in $p$ and $T$ are essentially negligible; the induced deviation of ray paths at the tangent point altitude (midway along the ray from $\mathrm{Tx}$ to $\mathrm{Rx}$ ) is smaller than $2 \mathrm{~m}$. To estimate their influence on $\mathcal{V}$ within the iterative retrieval process (Eqs. 2-4), we performed sensitivity testing by retrievals with all combinations of $\pm 1 \% p$ error and $\pm 1 \% T$ error. Taking for each species peak the highest (most conservative) uncertainties from these results yielded the estimates $\Delta \mathcal{V}$ summarized in Table 6 (fifth column).

It can be seen that ${ }^{13} \mathrm{CO}_{2}, \mathrm{C}^{18} \mathrm{OO}$, and $\mathrm{CH}_{4}$ are only linearly sensitive and therefore exhibit a $p / T$-induced uncertainty $\Delta \mathcal{V}$ of no more than $1 \%$, while the ${ }^{12} \mathrm{CO}_{2}$ and $\mathrm{H}_{2} \mathrm{O}$ lines react more sensitively with 6 and $3.5 \%$, respectively. These different $p / T$ sensitivities of different lines are mainly related to the quantum-mechanical state transitions of the lines (Schweitzer, 2010; Kirchengast and Schweitzer, 2011).

For a follow-on experiment it will be desirable to constrain the $p$ and $T$ knowledge along the ray to $\sim 1 \mathrm{hPa}$ and $\sim 0.3 \mathrm{~K}$ (e.g., by complementing the Tx, Rx, $p$, and $T$ measurements by several high-accuracy radiosonde launches beneath the ray path or balloon measurements near the ray path). This would reduce this uncertainty component to less than $0.2-$ $0.5 \%$ in the $\mathrm{GHG}$ retrievals.

\subsection{Statistical uncertainty in the measurements}

We now discuss statistical uncertainties estimated from the retrieved GHG data, including outlier rejection as a quality control process, in order to get a complementary view of the consistency of our results, i.e., complementary to the component-wise uncertainty estimation discussed above that aims at providing an "outer envelope" to all systematic and random uncertainties. The statistical uncertainties estimated here for the various species aim at finding out, under the assumption of random errors that can be reduced by averaging over individual retrieval results, how well the median and percentile estimates obtained can represent the validation data. In particular, we used averaging periods of about $10 \mathrm{~min}$ and determined medians and percentiles based on the ensemble of retrieved GHG values from the individual $4 \mathrm{~s}$ spectra falling into any such period.

More precisely, the first step of our statistical analysis is a quality control and outlier rejection; i.e., we aim to isolate those individually retrieved GHG values from the ensemble in any averaging period that derive from $4 \mathrm{~s}$ spectra of bad quality. To this end, we performed a first calculation of the median (representing the "mean"), and a calculation of the 16th and 84th percentiles (representing a $68 \%$ " $\pm 1 \sigma$ " range), from all individual retrievals of an IR-laser link data file over a period of at least $10 \mathrm{~min}$ if possible (maximum $15 \mathrm{~min}$; less if the data file or the rest of data file is shorter than $10 \mathrm{~min})$. Based on this output, all individual retrievals outside of the " $2.5 \cdot( \pm 1 \sigma)$ " range were rejected. Subsequently, as second step, we recalculated the median and the 16th and 84th percentiles from the remaining subset of individual retrievals, providing the final estimates of the mean and the $\pm 1 \sigma$ range for the given $\sim 10$ min period.

Figure 7 illustrates this method for a couple of example $\sim 10$ min periods for several ${ }^{12} \mathrm{CO}_{2}, \mathrm{H}_{2} \mathrm{O}$, and $\mathrm{CH}_{4}$ lines; the characteristics of all other retrieval ensembles look similar. The retrieval results are shown as a function of the underlying measured differential transmission values (Eq. 1) that flow into the retrieval algorithm (Eqs. 2-4). Given the near linearity of the algorithm, the resulting individual retrievals exhibit a near-linear dependence on the size of the measured $\Delta \mathcal{T}$ values.

All panels of Fig. 7 confirm that the retrieval ensembles in each $\sim 10$ min period clearly cluster around a certain average and are associated with a certain spread $( \pm 1 \sigma$ range) that arises from measurement errors in the individual $4 \mathrm{~s}$ spectra and influences of other uncertainties discussed above. Assuming the deviations from the average to be random, the measurement uncertainty of the $\sim 10 \mathrm{~min}$ averages is estimated by the " $\pm \sigma / \sqrt{n}$ " range. The degree of consistency of this comparatively narrow uncertainty with the validation data is of particular interest as a pointer to potential biases in the data (e.g., from spectroscopic parameter uncertainties or technical measurement biases; Betal2012).

The ${ }^{12} \mathrm{CO}_{2}$ data clustering and average indicate a nearly unbiased behavior (biases of $\sim 1 \%$ ), while the $\mathrm{H}_{2} \mathrm{O}$ data clustering and average look of similar quality but the large uncertainty range of the reference data allow no inferences on the biases. The $\pm 1 \sigma$ range for both species is on the order of 5-10\%, somewhat smaller than the combined uncer- 
tainty estimates above, which is meaningful as this spread does not reflect systematic uncertainties and validation-data uncertainties (in case of $\mathrm{H}_{2} \mathrm{O}$ ).

The clustering and the average of the $\mathrm{CH}_{4}$ ensemble (bottom panel) indicate that these measurement data had bias problems since both clusters (red and blue) appear to be located systematically below the "true" CRDS reference value (green line). This is consistent with the $\mathrm{CH}_{4}$ measurement problems pointed out by Betal2012. While Betal2012 refrained for this reason from any $\mathrm{CH}_{4}$ retrieval attempts, this result here still indicates that the $\mathrm{CH}_{4}$ spectra from the longpath measurements were also basically physically sound, albeit not of sufficient quality for quantitative consistency with accurate validation data.

The results from all $\sim 10$ min periods, based on all data files and inspecting all species analyzed, are discussed in the next section, where only the combined uncertainties and the measurement uncertainty of the $\sim 10$ min averages are visualized together with the reference data in order to enable a synthesis view.

\section{Retrieval results and validation}

The results from the analysis of the entire measured data set from all available data files, as summarized in Table 2, turn out to provide a successful first proof of concept of longpath IR-laser occultation measurements using the differential transmission principle as applied in the ACCURATE/LMIO mission concept. Figures 8 and 9 show the complete set of results from the two successful campaign nights 20-21 July and 21-22 July 2011. Reliable results have been obtained for all three targeted $\mathrm{CO}_{2}$ isotopes $\left({ }^{12} \mathrm{CO}_{2},{ }^{13} \mathrm{CO}_{2}, \mathrm{C}^{18} \mathrm{OO}\right)$, $\mathrm{H}_{2} \mathrm{O}$, and $\mathrm{CH}_{4}$.

The retrieval results for the three $\mathrm{CO}_{2}$ isotopes (upper three panels of Fig. 8, one per isotope) exhibit reliable repeatability of the retrieval results, for all species absorption lines exploited (Table 4). The average (median) values of the $\sim 10$ min periods are generally found to lie within $2 \%$ of the CRDS reference data, which themselves are consistent with narrow uncertainty of $<1 \%$ with the sampling flask cross-check measurements. We note that the isotopic abundance factors for calculating the isotope concentrations from the total $\mathrm{CO}_{2}$ concentration were taken from the HITRAN08 database, both for the retrieval results and the CRDS and flask reference data shown (for more information on up-todate mole fractions and isotopic abundance factors for $\mathrm{CO}_{2}$ isotopes see Coplen et al., 2002 and Chen et al., 2010; the differences to the HITRAN08 values are negligible for the purposes of this study).

The combined uncertainties (red error bars) are shown according to Table 6 and indicate that, within the uncertainty, all $\mathrm{CO}_{2}$ retrieval results are consistent with the CRDS reference data (green-filled circles). The statistical uncertainty of the averages (black error bars) is significantly smaller than
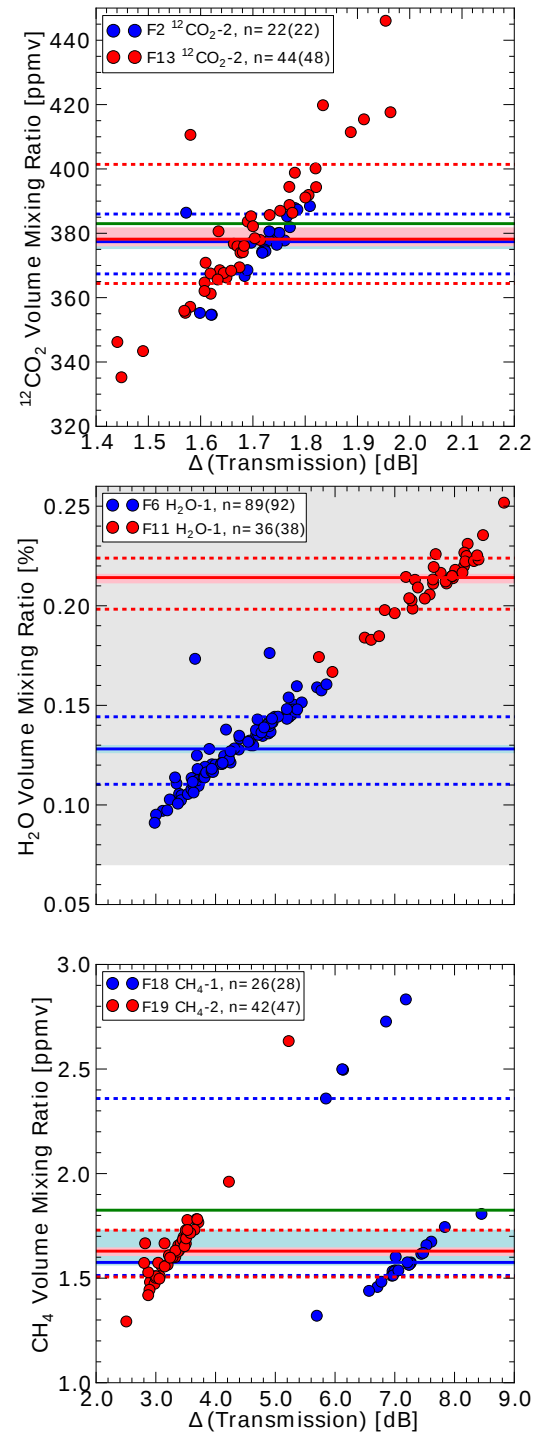

Figure 7. Examples of retrieved ensembles of volume mixing ratios within $\sim 10$ min periods for absorption lines of ${ }^{12} \mathrm{CO}_{2}$ (top panel, data from files $\mathrm{F} 2$ and F13), $\mathrm{H}_{2} \mathrm{O}$ (middle panel, data from files F6 and $\mathrm{F} 11$ ), and $\mathrm{CH}_{4}$ (bottom panel, data from files $\mathrm{F} 18$ and $\mathrm{F} 19$ ) as a function of the measured $\Delta \mathcal{T}$ (Eq. 1). Individual retrievals are shown (color-filled circles, one red and one blue example ensemble per panel) together with markers (horizontal lines and shaded areas) of the Tx/Rx-averaged CRDS reference value (green line, except for $\mathrm{H}_{2} \mathrm{O}$ ), the CRDS reference data uncertainty range (gray-shaded area, almost covering the $\mathrm{H}_{2} \mathrm{O}$ panel and almost invisibly small for ${ }^{12} \mathrm{CO}_{2}$ and $\mathrm{CH}_{4}$ ), the median value of the retrievals (red/blue solid lines, partially overlapping), the $\pm 1 \sigma$ range of the retrievals (red/blue dotted lines about median, partially overlapping), and the $\pm \sigma / \sqrt{n}$ range of the retrievals (light red/light blue-shaded areas, partially overlapping). The number of individual retrievals per ensemble $(n)$ is indicated in the legend both after the outlier rejection and before the outlier rejection (the latter shown as value in parentheses). 

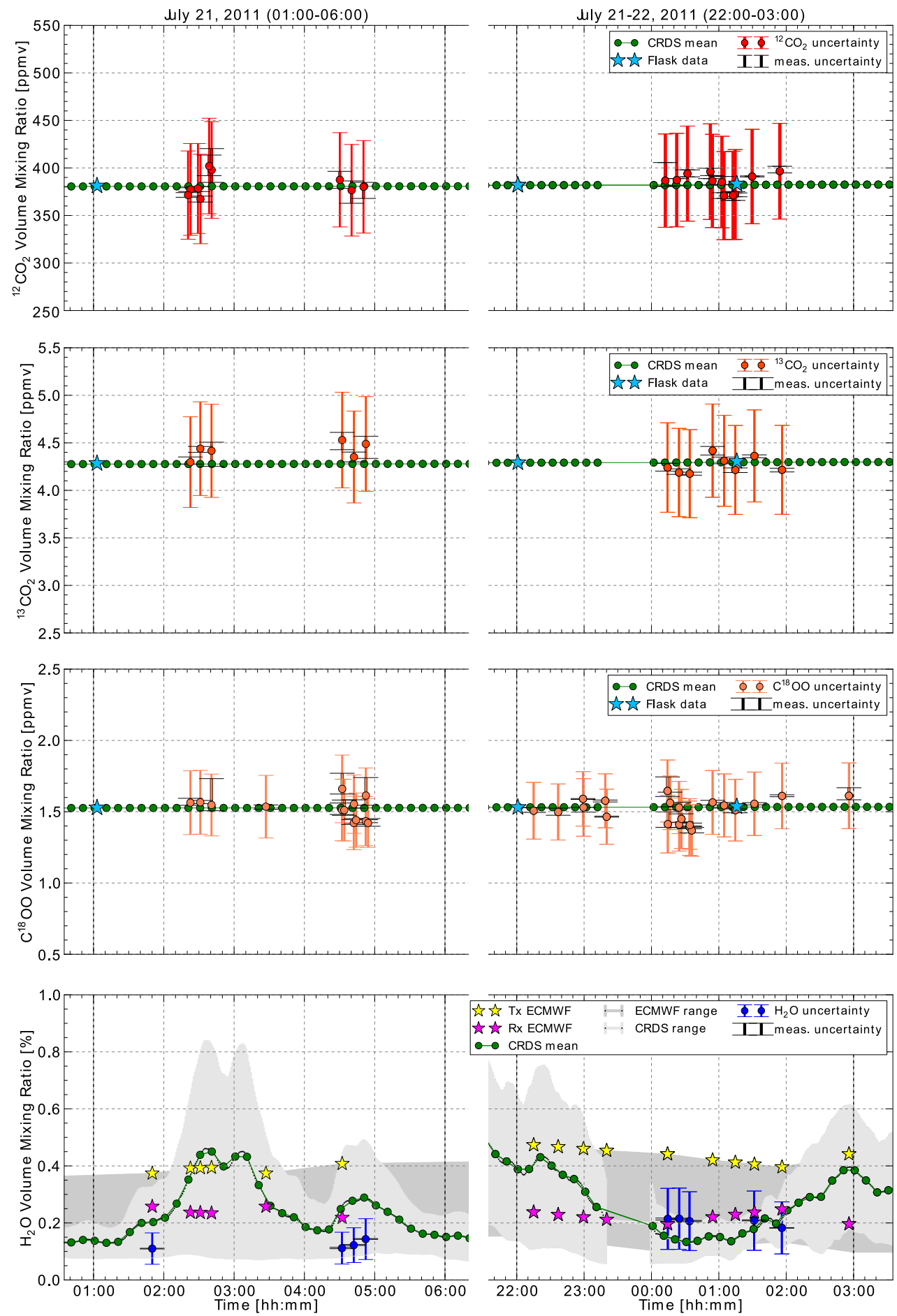

Figure 8. Retrieval results for ${ }^{12} \mathrm{CO}_{2}$ (top panel), ${ }^{13} \mathrm{CO}_{2}$ (upper-middle panel), $\mathrm{C}^{18} \mathrm{OO}$ (lower-middle panel), and $\mathrm{H}_{2} \mathrm{O}$ (bottom panel) volume mixing ratios for the $\sim 10$ min periods of all available species data from the two successful campaign nights of 21 July 2011 (within 01:00 to 06:00 UTC) and 21-22 July 2011 (within 22:00 to 03:00 UTC). For each available $\sim 10$ min period of a retrieved species, the average value (median; red/blue-filled circle), the estimated combined uncertainty (red/blue "error bar"), and the statistical uncertainty of the average (black error bar, generally overlapped by the red/blue error bar and of much smaller range) are shown. For validation reference, the 10 min averaged CRDS reference data (green-filled circles), the flask $\mathrm{CO}_{2}$ data (blue-colored stars in upper three panels), and the Tx/Rx-co-located ECMWF $\mathrm{H}_{2} \mathrm{O}$ data (yellow/magenta-colored stars in bottom panel) are shown. For $\mathrm{H}_{2} \mathrm{O}$ (bottom panel), also the uncertainty ranges of the CRDS data (light gray-shaded area) and ECMWF data (gray-shaded area) are indicated. 
the combined uncertainty and particularly narrow in case of a large ensemble size in a given $\sim 10 \mathrm{~min}$ period. This can be seen when comparing the results at certain times in Fig. 8 with the number of spectra in the data files available at those times (see Table 2). Likewise, the cases for which the average values (medians; red-filled circles) deviate more than about $2 \%$ from the reference values are usually associated with small ensemble sizes, such that also the statistical uncertainty of these averages is usually higher for these cases. A few cases show narrow statistical uncertainty despite stronger biases against the reference (e.g., the $\mathrm{C}^{18} \mathrm{OO}$ retrievals near 00:30 on 22 July); in these cases the measured spectra have been of poorer quality, typically from degraded signal-to-noise ratios.

The retrieval results for $\mathrm{H}_{2} \mathrm{O}$ (bottom panel of Fig. 8) show similar stability and narrow statistical uncertainty to the $\mathrm{CO}_{2}$ results, but the IR-laser link representation uncertainty of the CRDS reference data (light gray-shaded area) and the ECMWF reference data (gray-shaded area) is much larger, exceeding the uncertainty range estimated for the $\mathrm{H}_{2} \mathrm{O}$ retrievals. The reason for that is the high horizontal variability of water vapor as shown in Fig. 3 and described in Sect. 2.2. Under these broad uncertainties, we find the $\mathrm{H}_{2} \mathrm{O}$ retrieval results to be consistent with the reference data. However, under these circumstances, it is a fairly weak validation in quantitative terms.

Figure 9 shows the results for the $\mathrm{CH}_{4}$ retrievals within the final measurement period in the morning of 22 July 2011, where altogether just three $\sim 10 \mathrm{~min}$ periods are available, acquired around 06:00 UTC. As discussed in Sect. 4, and already visible in the example clusters of $\mathrm{CH}_{4}$ results shown in the bottom panel of Fig. 7, the $\mathrm{CH}_{4}$ retrieval averages (medians; orange-filled circles) exhibit a negative bias of about -10 to $-15 \%$ compared to the CRDS reference data. The latter agree very well (to within $<1 \%$ ) with the independent flask measurements taken about $2 \mathrm{~h}$ before (near 04:00 UTC).

The estimated combined uncertainty (orange error bars) according to Table 6 covers the reference data in only one of the three retrieval cases, signaling the more fundamental nature of the bias in the $\mathrm{CH}_{4}$ measurements as pointed out by Betal2012 and in Sect. 4 . The one case covering the reference data does so only because of the high estimated spectroscopic uncertainty of the $\mathrm{CH}_{4}-1$ absorption line. The quite narrow statistical uncertainty ranges of the averages are far from covering the reference data. However, even though the $\mathrm{CH}_{4}$ results are in this way found to be quantitatively inconsistent within the uncertainties with the validation reference data, these somewhat-biased results are still physically sound and indicate that equal measurement quality such as for $\mathrm{CO}_{2}$ would have led to consistency.

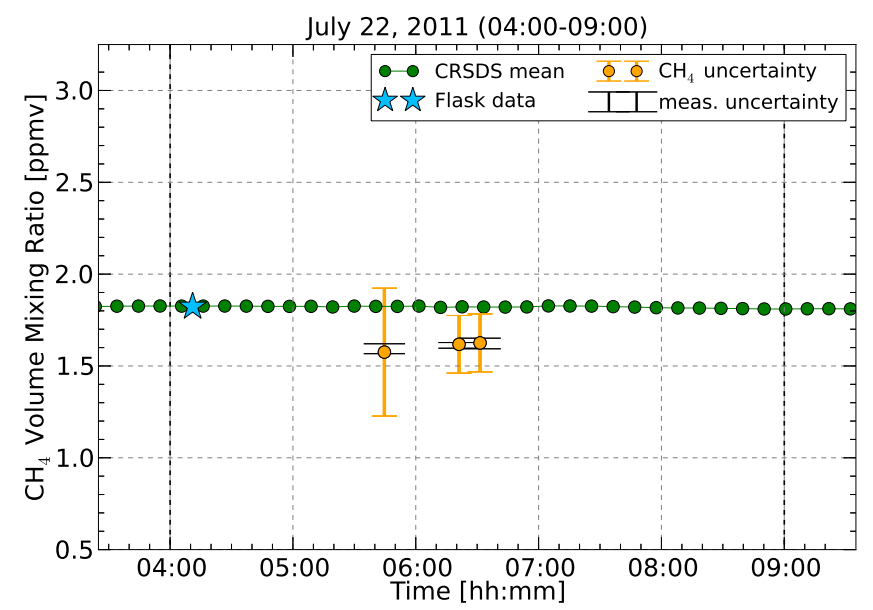

Figure 9. Retrieval results for $\mathrm{CH}_{4}$ volume mixing ratios for the three $\sim 10$ min periods of available data from the short campaign period allocated to $\mathrm{CH}_{4}$ in the morning of 22 July 2011 (within 04:00 to 09:00 UTC). The layout of the panel and the data shown are the same as for the $\mathrm{CO}_{2}$ panels in Fig. 8; see that caption for description.

\section{Summary and conclusions}

In this study we provided a detailed analysis of a pioneering proof-of-concept experiment: a ground-based IR-laser link over $144 \mathrm{~km}$ between the two Canary Islands La Palma and Tenerife was used to validate the differential transmission principle for long-path GHG measurements as proposed for spaceborne IR-laser occultation (Kirchengast and Schweitzer, 2011). Following the experiment introduction and initial analysis of a few sample spectra by Betal2012, we analyzed and validated the entire IR-laser link data set acquired during two successful campaign nights of 21 and 22 July 2011. Complementary independent data - comprised of weather station data, high-resolution ECMWF analysis fields, and CRDS and sampling flask GHG measurements, which had been acquired during the campaign at the Tx and $\mathrm{Rx}$ locations - served as reference data for evaluation and validation of the IR-laser link results.

We first introduced the preprocessed IR-laser link data and the validation data sets, followed by a description of the data processing setup and the differential transmission-based retrieval algorithm. We presented $\mathrm{GHG}$ volume mixing ratio results for the three main $\mathrm{CO}_{2}$ isotopes $\left({ }^{12} \mathrm{CO}_{2},{ }^{13} \mathrm{CO}_{2}\right.$, $\mathrm{C}^{18} \mathrm{OO}$ ) as well as for $\mathrm{H}_{2} \mathrm{O}$ and $\mathrm{CH}_{4}$. Furthermore, we performed a thorough retrieval uncertainty analysis, where we accounted for the following uncertainties: (i) uncertainties from a spectral correction, needed due to inadvertent spectral line broadening in the campaign measurements that occurred due to suboptimal Rx detection settings as discussed by Betal2012; (ii) uncertainty from spectroscopic parameter uncertainties due to limited accuracy of HITRAN08 parameters, especially of line intensity and air-broadened half width; and 
(iii) uncertainty from atmospheric parameters, due to limited accuracy of atmospheric pressure, temperature, and $\mathrm{H}_{2} \mathrm{O}$ in the retrieval and validation. The results for the $\mathrm{CO}_{2}$ isotopes, $\mathrm{H}_{2} \mathrm{O}$, and $\mathrm{CH}_{4}$ were then validated against the CRDS and flask reference data to assess their quality and consistency with these accurate and proven data.

The following main conclusions can be drawn.

1. We found the IR-laser link retrieval results for all three $\mathrm{CO}_{2}$ isotopes and for $\mathrm{H}_{2} \mathrm{O}$ robust and repeatable, and the retrieval results are consistent within uncertainties with the CRDS and flask reference data. The $\mathrm{CO}_{2} \sim$ 10 min averages were generally consistent within $\sim 2 \%$ with the reference data, while the high horizontal variability of $\mathrm{H}_{2} \mathrm{O}$ led to broad uncertainties (on the order of $50 \%$ ) in the inter-comparison, enabling for this species only a weak validation. For $\mathrm{CH}_{4}$, for which only a few campaign measurements existed, we found the results similarly robust and repeatable to those for the other species but somewhat biased (about -10 to $-15 \%$ ) against the reference data. This confirms the specific measurement problems pertaining to the $\mathrm{CH}_{4}$ spectra as discussed by Betal2012.

2. The estimated combined uncertainty in the retrieval results from spectral correction, spectroscopic parameters, limited $\mathrm{H}_{2} \mathrm{O}$ knowledge, and pressure and temperature uncertainties was generally found in the range of about $10-14 \%$ (except for $\mathrm{H}_{2} \mathrm{O}$, which is dominated by limited $\mathrm{H}_{2} \mathrm{O}$ variability knowledge, and for one $\mathrm{CH}_{4}$ absorption line with larger spectroscopic uncertainty). This estimated uncertainty is primarily dominated by the spectroscopic uncertainty (in HITRAN08 line parameters), followed by the spectral correction uncertainty being of second-most importance for the majority of the species absorption lines used. There is significant room to reduce these first-time-experiment uncertainties in a more consolidated follow-on experiment (to $<0.2-$ $0.5 \%$ ) as summarized in the outlook below.

3. Considering these first long-path IR-laser link demonstration results for the GHGs carbon dioxide, methane, and water vapor - and the related understanding and insight established by this study - from an overall perspective, we can conclude that the July 2011 Canary Islands experiment was successful in demonstrating the feasibility of monitoring GHGs in the free atmosphere by IR-laser occultation employing the differential transmission principle. The ACCURATE/LMIO mission concept (Kirchengast and Schweitzer, 2011) thus has a sound basis in this respect.

As an outlook for the next steps, in particular for a more consolidated ground-based or airborne follow-on experiment, the main priorities for improvements of the experiment include a reduction of uncertainties in all components of the combined uncertainty budget and use of improved Tx and $\mathrm{Rx}$ technologies.

Regarding the uncertainties, spectral correction uncertainties can be reduced to $<0.1 \%$ by optimized control of experiment settings and an improved signal-to-noise ratio at the Rx. Spectroscopic uncertainties can be reduced to $<0.2 \%$ by dedicated high-accuracy laboratory spectroscopy for targeted absorption lines (Kirchengast and Schweitzer, 2011; Harrison et al., 2011). Uncertainties due to limited $\mathrm{H}_{2} \mathrm{O}$ knowledge can be reduced to $<0.2-0.5 \%$ by providing $\mathrm{H}_{2} \mathrm{O}$ validation data to within an accuracy of $5 \%$ for the IRlaser link (e.g., from a co-aligned microwave link with suitable frequencies near $23 \mathrm{GHz}$, such as those that are part of the LMIO method). Pressure and temperature uncertainties can be reduced to $<0.2-0.5 \%$ by ensuring an accuracy of $\sim 1 \mathrm{hPa}$ and $\sim 0.3 \mathrm{~K}$ along the link (e.g., by complementing the $\mathrm{Tx}$ and $\mathrm{Rx}$ atmospheric data by several radiosonde launches or balloon-borne observations). Overall, this implies that a follow-on experiment should constrain the combined uncertainty of GHG retrievals to smaller than $0.5 \%$, enabling the accuracy and stability of IR-laser occultation also to be proved rigorously.

Regarding improved technologies, the use of more accurate wavemeters (high-accuracy frequency stabilization) and somewhat-amplified IR-laser signals (to a few $100 \mathrm{~mW}$ ) at the $\mathrm{Tx}$, of a (semi-)automatic pointing and tracking system for the Tx-to-Rx laser link, and of a more elaborated multichannel detection system at the Rx will enable the achievement of the narrow uncertainty budget of $<0.5 \%$ from the technology side.

Preparations in both directions, uncertainty reduction and technology improvement, are ongoing. Given the encouraging results of the first-time experiment reported in this study it is hoped that a more rigorous follow-on experiment will be conducted within the next 2 years. This will constitute a vital further step, among others, towards a full spaceborne realization of an ACCURATE/LMIO mission.

Acknowledgements. The July 2011 Canary Islands experiment, providing the basis for this study, was funded by the European Space Agency's Support to Science Element (STSE) and supported by the Earth Observation Future Missions program, including use of ESA's OGS facility. All contributors beyond the authors of this study are thanked for their support to this experiment, including the owners and operators of the Northern Optical Telescope (NOT) for allowing the use of their facilities. RFM and FASCODE were provided by A. Dudhia (Univ. of Oxford, UK) via http://www.atm.ox.ac.uk/RFM, HITRAN was provided by L. Rothman (Harvard Univ., USA) via http://www.cfa.harvard.edu/hitran, and atmospheric analysis fields were made accessible by the ECMWF (Reading, UK). Local meteorological data were obtained at the Tx site from the NOT weather station via http://www.not.iac.es/weather/ and at the Rx site from the Global Oscillation Network Group (GONG) weather station via http://www.iac.es/weather/otdata/. This research, including development work on the simulation and data processing integrated 
within the xEGOPS/EGOPS system, was funded by ESA under the ACTLIMB, IRDAS, IRDAS-EXP, and AEXPWIND studies and partially by FFG-ALR (Austria) under the ACCU-Clouds study.

Edited by: S. Buehler

\section{References}

Bovensmann, H., Burrows, J. P., Buchwitz, M., Frerick, J., Noël, S., Rozanov, V. V., Chance, K. V., and Goed, A. P. J.: SCIAMACHY: mission objectives and measurement modes, J. Atmos. Sci., 56, 127-150, doi:10.1175/15200469(1999)056<0127:SMOAMM>2.0.CO;2, 1999.

Brailsford, G. W., Stephens, B. B., Gomez, A. J., Riedel, K., Mikaloff Fletcher, S. E., Nichol, S. E., and Manning, M. R.: Long-term continuous atmospheric $\mathrm{CO}_{2}$ measurements at Baring Head, New Zealand, Atmos. Meas. Tech., 5, 3109-3117, doi:10.5194/amt-5-3109-2012, 2012.

Brooke, J. S. A., Bernath, P. F., Kirchengast, G., Thomas, C. B., Wang, J.-G., Tereszchuk, K. A., González Abad, G., Hargreaves, R. J., Beale, C. A., Harrison, J. J., Schweitzer, S., Proschek, V., Martin, P. A., Kasyutich, V. L., Gerbig, C., Kolle, O., and Loescher, A.: Greenhouse gas measurements over a $144 \mathrm{~km}$ open path in the Canary Islands, Atmos. Meas. Tech., 5, 2309-2319, doi::10.5194/amt-5-2309-2012, 2012.

Chahine, M. T., Pagano, T. S., Aumann, H. H., Atlas, R., Barnet, C., Blaisdell, J., Chen, L., Divakarla, M., Fetzer, E. J., Goldberg, M., Gautier, C., Granger, S., Hannon, S., Irion, F. W., Kakar, R., Kalnay, E., Lambrigsen, B. H., Lee, S.-Y., Le Marshall, J., McMillan, W. W., McMillin, L., Olsen, E. T., Revercomb, H., Rosenkranz, P., Smith, W. L., Staelin, D., Strow, L. L., Susskind, J., Tobin, D., Wolf, W., and Zhou, L.: AIRS: improving weather forecasting and providing new data on greenhouse gases, B. Am. Meteorol. Soc., 87, 911-926, doi:10.1175/BAMS87-7-911, 2006.

Chalon, G., Cayla, F., and Diebel, D.: IASI: an advanced sounder for operational meteorology, in: Proc. 52nd Int. Astronautical Congress, 1-9, available at: http://smsc.cnes.fr/documentation/ IASI/Publications/PRESENTATION_IAF_2001.pdf, 2001.

Chen, H., Winderlich, J., Gerbig, C., Hoefer, A., Rella, C. W., Crosson, E. R., Van Pelt, A. D., Steinbach, J., Kolle, O., Beck, V., Daube, B. C., Gottlieb, E. W., Chow, V. Y., Santoni, G. W., and Wofsy, S. C.: High-accuracy continuous airborne measurements of greenhouse gases $\left(\mathrm{CO}_{2}\right.$ and $\left.\mathrm{CH}_{4}\right)$ using the cavity ring-down spectroscopy (CRDS) technique, Atmos. Meas. Tech., 3, 375386, doi:10.5194/amt-3-375-2010, 2010.

Coplen, T. B., Böhlke, J. K., De Bièvre, P., Ding, T., Holden, N. E., Hopple, J. A., Krouse, H. R., Lamberty, A., Peiser, H. S., Révész, K., Rieder, S. E., Rosman, K. J. R., Roth, E., Taylor, P. D. P., Vocke, R. D. J., and Xiao, Y. K.: Isotope-abundance variations of selected elements, Pure Appl. Chem., 74, 19872017, doi:10.1351/pac200274101987, 2002.

Desjardins, R. L., MacPherson, J. I., Schuepp, P. H., and Karanja, F.: An evaluation of aircraft flux measurements of $\mathrm{CO}_{2}$, water vapor and sensible heat, Bound.-Lay. Meteorol., 47, 55-69, doi:10.1007/BF00122322, 1989.

Dudhia, A.: Reference Forward Model RFM: Inst. of Atmos., Oceanic and Planet. Phys., Univ. of Oxfor, Oxford, UK, available at: http://eodg.atm.ox.ac.uk/RFM/ (last access: 7 August 2015), 2008.

FASCODE: RFM Website - FASCODE Model Atmospheres: Inst. of Atmos., Oceanic and Planet. Phys., Univ. of Oxford, Oxford, UK, available at: http://eodg.atm.ox.ac.uk/RFM/atm/ (last access: 7 August 2015), 2008.

From, E. and Keeling, C. D.: Reassessment of late 19th century atmospheric carbon dioxide variations in the air of western Europe and the British Isles based on an unpublished analysis of contemporary air masses by G. S. Callendar, Tellus B, 38, 87-105, doi:10.1111/j.1600-0889.1986.tb00092.x, 1986.

Gorbunov, M. E. and Kirchengast, G.: Fluctuations of radio occultation signals in $\mathrm{X} / \mathrm{K}$ band in the presence of anisotropic turbulence and differential transmission retrieval performance, Radio Sci., 42, RS4025, doi:10.1029/2006RS003544, 2007.

Gurk, Ch., Fischer, H., Hoor, P., Lawrence, M. G., Lelieveld, J., and Wernli, H.: Airborne in-situ measurements of vertical, seasonal and latitudinal distributions of carbon dioxide over Europe, Atmos. Chem. Phys., 8, 6395-6403, doi:10.5194/acp-8-6395-2008, 2008.

Hamazaki, T., Kaneko, Y., and Kuze, A.: Carbon dioxide monitoring from the GOSAT satellite, in: Proceedings of the XXth ISPRS Conference, 1-3, available at: http://http://www.isprs.org/ proceedings/XXXV/congress/comm7/papers/43.pdf, 2004.

Harrison, J. J., Bernath, P. F., and Kirchengast, G.: Spectroscopic requirements for ACCURATE, a microwave and infrared-laser occultation satellite mission, J. Quant. Spectrosc. Ra., 112, 23472354, 2011.

Heimann, M.: Obituary: Charles David Keeling 1928-2005, Nature, 437, 331, doi:10.1038/437331a, 2005.

Keeling, C. D.: Is carbon dioxide from fossil fuel changing man's environment?, P. Am. Philos. Soc., 114, 10-17, 1970.

Kirchengast, G. and Schweitzer, S.: Climate benchmark profiling of greenhouse gases and thermodynamic structure and wind from space, Geophys. Res. Lett., 38, L13701, doi:10.1029/2011GL047617, 2011.

Kirchengast, G., Bernath, P. F., Buehler, S., Durry, G., Facheris, L., Gerbig, C., Haimberger, L., Harris, J., Hauchecorne, A., Kurölä, E., Larsen, G. B., Sausen, R., Anthes, R. A., Gorbunov, M. E., Kursinski, E. R., Leroy, S. S., Trenberth, K., Randel, B., Gille, J., and Tsuda, T.: ACCURATE - climate benchmark profiling of greeenhouse gases and thermodynamic variables and wind from space (ESA Earth Explorer Opportunity Mission EE-8 proposal), Sci. Rep. 36-2010, Wegener Center Verlag, Graz, Austria, available at: http://www.wegcenter.at/wcv (last access: 7 August 2015), 2010.

Kursinski, E. R., Syndergaard, S., Flittner, D., Feng, D., Hajj, G., Herman, B., Ward, D., and Yunck, T.: A microwave occultation observing system optimized to characterize atmospheric water, temperature and geopotential via absorption, J. Atmos. Ocean. Tech., 19, 1897-1914, doi:10.1175/15200426(2002)019<1897:AMOOSO>2.0.CO;2, 2002.

Messerschmidt, J., Chen, H., Deutscher, N. M., Gerbig, C., Grupe, P., Katrynski, K., Koch, F.-T., Lavrič, J. V., Notholt, J., Rödenbeck, C., Ruhe, W., Warneke, T., and Weinzierl, C.: Automated ground-based remote sensing measurements of greenhouse gases at the Białystok site in comparison with collocated in situ measurements and model data, Atmos. Chem. Phys., 12, 6741-6755, doi:10.5194/acp-12-6741-2012, 2012. 
Plach, A., Proschek, V., and Kirchengast, G.: Profiling wind and greenhouse gases by infrared-laser occultation: algorithm and results from end-to-end simulations in windy air, Atmos. Meas. Tech., 8, 2813-2825, doi:10.5194/amt-8-2813-2015, 2015.

Proschek, V., Kirchengast, G., and Schweitzer, S.: Greenhouse gas profiling by infrared-laser and microwave occultation: retrieval algorithm and demonstration results from end-to-end simulations, Atmos. Meas. Tech., 4, 2035-2058, doi:10.5194/amt-42035-2011, 2011.

Proschek, V., Kirchengast, G., Emde, C., and Schweitzer, S.: Greenhouse gas profiling by infrared-laser and microwave occultation in cloudy air: results from end-to-end simulations, J. Geophys. Res. Atmos., 119, 12372-12390, doi:10.1002/2014JD021938, 2014.

Rothman, L. S., Rinsland, C. P., Goldman, A., Massie, S. T., Edwards, D. P., Flaud, J.-M., Perrin, A., Camy-Peyret, C., Dana, V., Mandin, J.-Y., Schroeder, J., McCann, A., Gamache, R. R., Wattson, R. B., Yoshino, K., Cahnce, K. V., Jucks, K. W., Brown, L. R., Nemtchinov, V., and Varanasi, P.: The HITRAN molecular spectrsoscopic database and HAWKS (Hitran Atmospheric WorKStation): 1996 edition, J. Quant. Spectrosc. Ra., 60, 665-710, 1998.

Rothman, L. S., Gordon, I. E., Barbe, A., Benner, D. C., Bernath, P. F., Birk, M., Boudon, V., Brown, L. R., Campargue, A., Champion, J.-P., Chance, K., Coudert, L. H., Dana, V., Devi, V. M., Fally, S., Flaud, J.-M., Gamache, R. R., Goldman, A., Jacquemart, D., Kleiner, I., Lacome, N., Lafferty, W. J., Mandin, J.-Y., Massie, S. T., Mikhailenko, S. N., Miller, C. E., Moazzen-Ahmadi, N., Naumenko, O. V., Nikitin, A. V., Orphal, J., Perevalov, V. I., Perrin, A., Predoi-Cross, A., Rinsland, C. P., Rotger, M., Šimečková, M., Smith, M. A. H., Sung, K., Tashkun, S. A., Tennyson, J., Toth, R. A., Vandaele, A. C., and Vander Auwera, J.: The HITRAN 2008 molecular spectroscopic database, J. Quant. Spectrosc. Ra., 110, 533572, doi:10.1016/j.jqsrt.2009.02.013, 2009.

Rothman, L. S., Gordon, I. E., Babikov, Y., Barbe, A., Benner, D. C., Bernath, P. F., Birk, M., Bizzocchi, L., Boudon, V., Brown, L. R., Campargue, A., Chance, K., Cohen, E. A., Coudert, L. H., Devi, V. M., Drouin, B. J., Fayt, A., Flaud, J.- M., Gamache, R. R., Harrison, J. J., Hartmann, J.-M., Hill, C., Hodges, J. T., Jacquemart, D., Jolly, A., Lamouroux, J., Roy, R. J. L., Li, G., Long, D. A., Lyulin, O. M., Mackie, C. J., Massie, S. T., Mikhailenko, S., Mueller, H. S. P., Naumenko, O. V., Nikitin, A. V., Orphal, J., Perevalov, V., Perrin, A., Polovtseva, E. R., Richard, C., Smith, M. A. H., Starikova, E., Sung, K., Tashkun, S., Tennyson, J., Toon, G. C., Tyuterev, V. G., and Wagner, G.: The HITRAN2012 molecular spectroscopic database, J. Quant. Spectrosc. Ra., 130, 4-50, doi:10.1016/j.jqsrt.2013.07.002, 2013.

Schweitzer, S.: The ACCURATE concept and the infrared laser occultation technique: mission design and assessment of retrieval performacne, Ph.D. thesis, Sci. Rep. 34-2010, Wegener Center Verlag, Graz, Austria, available at: http://www.wegcenter.at/wcv (last access: 7 August 2015), 2010.
Schweitzer, S., Kirchengast, G., and Proschek, V.: Atmospheric influences on infrared-laser signals used for occultation measurements between Low Earth Orbit satellites, Atmos. Meas. Tech., 4, 2273-2292, doi:10.5194/amt-4-2273-2011, 2011a.

Schweitzer, S., Kirchengast, G., Schwärz, M., Fritzer, J. M., and Gorbunov, M. E.: Thermodynamic state retrieval from microwave occultation data and performance analysis based on end-to-end simulations, J. Geophys. Res., 116, D10301, doi:10.1029/2010JD014850, 2011b.

Syndergaard, S., and Kirchengast, G.: An Abel transform for deriving line-of-sight wind profiles from LEO-LEO infrared laser occultation measurements, J. Geophys. Res. Atmos., in review, 2015.

Vadrevu, K. P. and Choi, Y.: Wavelet analysis of airborne $\mathrm{CO}_{2}$ measurements and related meteorological parameters over heterogeneous landscapes, Atmos. Res., 102, 77-90, doi:10.1016/j.atmosres.2011.06.008, 2011.

WMO: Report of the 16th WMO/IAEA meeting of experts on carbon dioxide, other greenhouse gases, and related tracers measurement techniques (GGMT-2011), GAW Report No. 206, WMO TD No. 1553, Wellington, New Zealand, available at: http://www.wmo.int/pages/prog/arep/gaw/documents/Final_ GAW_206_web.pdf (last access: 7 August 2015), 2012.

Wunch, D., Toon, G. C., Wennberg, P. O., Wofsy, S. C., Stephens, B. B., Fischer, M. L., Uchino, O., Abshire, J. B., Bernath, P., Biraud, S. C., Blavier, J.-F. L., Boone, C., Bowman, K. P., Browell, E. V., Campos, T., Connor, B. J., Daube, B. C., Deutscher, N. M., Diao, M., Elkins, J. W., Gerbig, C., Gottlieb, E., Griffith, D. W. T., Hurst, D. F., Jiménez, R., Keppel-Aleks, G., Kort, E. A., Macatangay, R., Machida, T., Matsueda, H., Moore, F., Morino, I., Park, S., Robinson, J., Roehl, C. M., Sawa, Y., Sherlock, V., Sweeney, C., Tanaka, T., and Zondlo, M. A.: Calibration of the Total Carbon Column Observing Network using aircraft profile data, Atmos. Meas. Tech., 3, 1351-1362, doi:10.5194/amt-3-1351-2010, 2010.

Yang, Z., Toon, G. C., Margolis, J. S., and Wennberg, P. O.: Atmospheric $\mathrm{CO}_{2}$ retrieved from ground-based near IR solar spectra, Geophys. Res. Lett., 29, 53-1-53-4, doi:10.1029/2001GL014537, 2002.

Yokota, T., Yoshida, Y., Eguchi, N., Ota, Y., Tanaka, T., Watanabe, H., and Maksyutov, S.: Global concentrations of $\mathrm{CO}_{2}$ and $\mathrm{CH}_{4}$ retrieved from GOSAT: first preliminary results, SOLA, 5, 160-163, 2009.

Yoshida, Y., Ota, Y., Eguchi, N., Kikuchi, N., Nobuta, K., Tran, H., Morino, I., and Yokota, T.: Retrieval algorithm for $\mathrm{CO}_{2}$ and $\mathrm{CH}_{4}$ column abundances from short-wavelength infrared spectral observations by the Greenhouse gases observing satellite, Atmos. Meas. Tech., 4, 717-734, doi:10.5194/amt-4-717-2011, 2011. 